\title{
Holistic spatial semantics and post-Talmian motion event typology: A case study of Thai and Telugu
}

\author{
${ }^{1}$ University of Cothenburg, Gothenburg, Sweden \\ ${ }^{2}$ University of Hyderabad, Hyderabad India \\ 3 Lund University, Lund, Sweden, E-mail: jordan.zlatev@semiotik.lu.se \\ ${ }^{4}$ Osmania University, Hyderbad India
}

\begin{abstract}
:
Leonard Talmy's influential binary motion event typology has encountered four main challenges: (a) additional language types; (b) extensive "type-internal" variation; (c) the role of other relevant form classes than verbs and "satellites;" and (d) alternative definitions of key semantic concepts like Motion, Path and Manner. After reviewing these issues, we show that the theory of Holistic Spatial Semantics provides analytical tools for their resolution. In support, we present an analysis of motion event descriptions by speakers of two languages that are troublesome for the original typology: Thai (Tai-Kadai) and Telugu (Dravidian), based on the Frog-story elicitation procedure. Despite some apparently similar typological features, the motion event descriptions in the two languages were found to be significantly different. The Telugu participants used very few verbs in contrast to extensive case marking to express Path and nominals to express Region and Landmark, while the Thai speakers relied largely on serial verbs for expressing Path and on prepositions for expressing Region. Combined with previous research in the field, our findings imply (at least) four different clusters of languages in motion event typology with Telugu and Thai as representative of two such clusters, languages like French and Spanish representing a third cluster, and Swedish and English a fourth. This also implies that many other languages like Italian, Bulgarian, and Basque will appear as "mixed languages," positioned between two or three of these clusters.
\end{abstract}

Keywords: path, semantic typology, verbs, case marking, conflation, distribution, composition, covert expression DOI: $10.1515 /$ cogsem-2018-2002

\section{Introduction}

One of the most influential models in semantic typology around the turn of the century was the "motion event typology" of Talmy (1991, 2000a, and 2000b). The original proposal claimed that all languages can be treated as either verb-framed (e.g. the Romance and Semitic languages), or satellite-framed (e.g. the Germanic and Slavonic languages) on the basis of their predominant means of expressing the semantic category of Path: (a) either in the main verb or (b) in a so-called satellite, typically a prefix (e.g. Russian v-hodit, 'in-walk') or verbal particle (e.g. Swedish springa in, 'run into'). This elegant and simple model has provoked both extensive research and a number of challenges over the past two decades (cf. Berthele 2013; Imbert 2012; Slobin 2017). One problem is that that the two original language types do not seem to be sufficient, and a "third type" has been proposed (Slobin 2004; Zlatev and Yangklang 2004). Another issue is that extensive variation within the proposed types (Ibarretxe-Antuñano 2009) and even within single languages depending on dialectal factors (Berthele 2013; Duggirala 2011) has called the coherence of the notion "language type" into question. A currently influential proposal is to regard the typology as concerning specific constructions rather than languages (Croft et al. 2010). But most seriously, doubt has been cast on the coherence of basic concepts in the theory such as Motion, Path, Manner, "satellite," and "framing" (Bohnemeyer et al. 2007; Imbert 2012; 2007; Zlatev et al. 2010). We summarize these issues in Section 2 and agree with Berthele (2013: 73) in his call for the need "to come up with a better account of the variation discovered [...] in the field of the linguistic construal of motion events." On the other hand, we also agree with Beavers et al. (2010:332) who state that "any viable account should illuminate why 
Talmy's typology is so close to being right," given that it has appeared, at least temporarily, as such a useful tool in the analysis of cross-linguistic variation in motion expression. In this sense, current work on motion event semantics can be regarded as "post-Talmian:" the field is both indebted to the model and agrees that a more adequate theory is called for.

In this spirit, the theoretical framework of Holistic Spatial Semantics, henceforth HSS (Zlatev 1997 and 2003 ; Fagard et al. 2013; Blomberg 2014) described in Section 3 builds on Talmy's insights while providing a more extensive and rigorously defined set of categories of motion semantics as well as of possible ways in which they may be expressed across languages. Thus, it offers a way to address the issues of the original model mentioned above.

To demonstrate its validity, we here examine data from two languages that have been challenging for motion event typology. One of these is Thai (Tai-Kadai, Thailand), which along with other serial-verb languages has been attributed to a third "equipollently-framed" language type (Slobin 2004) where the categories of Path and Manner are expressed in forms with equal grammatical status. The other is Telugu (Dravidian, India), which has also been typologically puzzling, with features such as Path verbs like bayata padu 'exit,' but also Manner verbs used in constructions that imply "boundary crossing" as in (1) - uncommon for more typical "verbframed" languages like Turkish (Özcaliskan 2013) — and extensive use of case-marking (Naidu and Duggirala 2011).

(1)

$\begin{array}{lll}\text { pillavaadu } & \text { skuulu-loo-ki } & \text { parigettaa-du } \\ \text { boy[NOM.SG] } & \text { school-in-DAT } & \text { run.PST-AGR }\end{array}$

'The boy ran into the school.'

Given the extensive variation in the expression of motion events, it has become mandatory to complement the use of native-speaker intuitions with the analysis of language use, either spontaneous or elicited. For this purpose, we analyze elicited "frog stories" (Berman and Slobin 1994) from 10 adult speakers per language, allowing us to perform a qualitative and quantitative comparison in the descriptions of motion events in Telugu and Thai. In Section 4, we describe the methodology of our empirical study and our major findings. To anticipate, while on the level of semantic types (categories) the motion event descriptions of the two languages may appear similar, we find major differences on the quantitative level of instances of categories and constructions used. On closer inspection, these differences make perfect sense given the prevalent grammatical constructions in each language: serial-verb constructions (Thai) and case-marking (Telugu). In Section 5, we conclude by summarizing how well we have fulfilled our aims: (a) to present HSS, a relatively less-known theoretical framework for the analysis of space and motion semantics, to a broader audience; (b) to demonstrate its ability to address key issues in the field; and (c) to provide illuminating qualitative and quantitative analysis of lesser studied languages such as Telugu and Thai.

\section{Problems with Talmy's binary typology}

As pointed out in the introduction, empirical, theoretical and conceptual/definitional challenges for the Talmian typology have been accumulating over the past two decades, leading "from a dichotomy to cacophony" (Imbert 2012: 248). We may group these issues in four categories, formulated as questions. In the review, we consider these both as problems for the original model, and as motivations for an alternative. In Section 3, we show how our theoretical framework provides answers to these four questions.

\subsection{How many language types?}

Some, though by all means not all, Germanic and Romance languages have served as "prototypes" or "templates" for the original typology (Imbert 2012: 252). Indeed, if one were to localize the expression of Path, or rather translocation (see Section 2.4), in a single item, this would be the particle/satellite in ('in') in the Swedish example (2) and the verb entrer ('enter') in the French example (3). Conversely, the semantic category Manner (of motion) is expressed in (2) in the verb springa ('run'), while relegated to an optional participle en courant ('running') in (3). 
(2)

$\begin{array}{llllll}\text { Sven } & \text { sprang } & \text { in } & i & \text { rumm-et } & \text { (Swedish) } \\ \text { Sven } & \text { run.PST } & \text { in(PRT) } & \text { in(PREP) } & \text { room-DEF } & \end{array}$

'Sven ran into the room.'

(3)

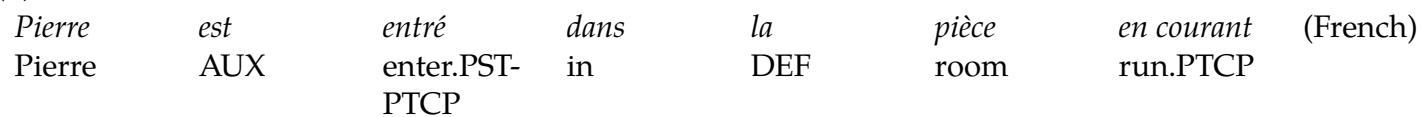

'Pierre entered the room running.'

When a wider sample of languages was considered, this simple pattern became questionable. In serial verb languages like Thai (Zlatev and David 2003; Zlatev and Yangklang 2004) and Ewe (Niger-Congo) (Ameka and Essegbey 2006 and 2013), both Path and Manner are expressed by full verbs, none of which are subordinate, with Manner typically preceding Path, as shown in (4) and (5).

(4)

$\begin{array}{lllllll}\text { priida } & \text { wîn } & \text { khâw } & \text { pay/maa } & \text { nay } & \text { hôy } & \text { (Thai) } \\ \text { Priida } & \text { run } & \text { enter } & \text { go/come } & \text { in } & \text { room } & \end{array}$

'Priida ran into the room, away from/towards the speaker.'

(5)

\begin{tabular}{|c|c|c|c|c|}
\hline é-tá & do & le & $x \mathrm{O}-a$ & me \\
\hline 3SG-crawl & exit & LOC & $\begin{array}{l}\text { building- } \\
\text { DEF }\end{array}$ & containing_region_of \\
\hline
\end{tabular}

'S/he crawled out of the room.' (Ameka and Essegbey 2006: 394)

In addition, Thai serial verb phrases like the one in (4) also show the need to distinguish between Path verbs like khâw ('enter') and Deictic verbs like pay ('go') and maa ('come'), the latter always appearing in the last position in the verb complex (Zlatev and Yangklang 2004) ${ }^{2}$, and in some cases used in their grammaticalized senses as markers of perfective aspect (Thepkanjana 1986). This is apparently very similar to the way motion events are expressed in Mandarin Chinese (Chen and Guo 2009). However, it is possible that Path expressions like Mandarin guò 'pass' have undergone a degree of grammaticalization when they appear in contexts like (6a), as opposed to when they appear as independent verbs, as in (6b), prompting Talmy (2009) to argue for their status as "satellites" in the first case.

(6a)

$\begin{array}{llllll}\text { taa } & \text { zǒu } & \text { guò } & l e & \text { goong-yuán } & \text { (Mandarin) } \\ \text { she/he } & \text { walk } & \text { pass } & \text { PRF } & \text { park }\end{array}$

'She/he walked past/across the park.' (Talmy 2009: 398)

$(6 b)$

\begin{tabular}{|c|c|}
\hline $\begin{array}{l}\text { taa } \\
\text { she/he }\end{array}$ & $\begin{array}{l}\text { guò } \\
\text { pass }\end{array}$ \\
\hline
\end{tabular}

'She/he was observed to pass the park as part of a longer time.' (Ibid.)

Still, serial verb languages have been troublesome for the binary typology. Grouping them together with those in which Manner and Path form lexical compounds, as in Athabascan (Dené-Yeniseian, Canada), Slobin (2004 and 2006) made the case for a third language type, which he called equipollently-framed, alluding to the equal grammatical status of Path and Manner in such languages.

But why stop at three types? As we show in this article, case-marking on the noun phrases (expressing what Talmian typology calls the "ground element" and what we refer to as Landmark, see Section 3) is the dominant way of expressing Path in Telugu, and possibly all languages with locative case systems, such as the Finno-Ugric languages. Since case markers are clearly not "satellites" to the verb (see Section 2.3), that would seem to imply that we have a fourth language type that we could call "case-framed" (Zlatev et al. 2015). 
Imbert (2012) mentions, with a touch of irony, the possibility of an additional type: "voice-framing." In Tagalog (Austronesian), the difference between 'walk on the bridge' and 'walk to the bridge' is expressed in verbal morphological markers for grammatical voice, with reference to unpublished work by Jean-Michel Fortis and Benjamin Fagard. In sum, the original binary typology of languages appears to be too limited to capture the dimensions of variation across the world's languages.

\subsection{Language types or construction types?}

One option to this conundrum has been to state that the typology applies not to languages as such, but to specific constructions within them. Following Aske's (1989) early observation that some languages like Spanish strongly prefer Path-verbs in the description of boundary-crossing (Slobin and Hoiting 1994) events but have no problem using Manner verbs like courir ('run') if the boundary is not traversed, this parameter has received much attention in the literature (e.g. Özcaliskan 2013; Fagard et al. 2013). Talmy (2000b: 64) proposed treating this in terms of a "split system" in an analogous way to how some languages use either accusative or ergative alignment in different constructions (DeLancey 1981; Garrett 1990).

But since all languages may end up as being more or less "split," with some constructions preferring Path verbs while others preferring Manner-verbs and satellites, as well as other kinds of mapping patterns between the expression and meaning planes:

One may suggest that a typology of Path expression should not aim to classify languages into discrete framing types, but to classify strategies adopted in languages for the expression of Path; such strategies rely on a morphosyntactic tool box, a set of constructions which allow a variety of expressions and also constrains such variety. (Imbert 2012: 253)

Croft et al. (2010) analyze the two Talmian types in terms of such constructions, and in addition point out the existence of symmetrical framing (corresponding to Slobin's notion of "equipollently framed"), and double framing, when Path is expressed in more than one element in the utterance. As we note in Section 3, this is a strategy that is widely spread across languages, qualifying as one type of distributed expression in HSS.

Still, re-formulating the typology in terms of construction types is not inconsistent with seeing combinations of such types as coalescing into language types, given that languages may be regarded as structured inventories of constructions (Barðdal 2013; Langacker 1987; our emphasis) with yet to be determined patterns of constructional co-variation. As often quoted, "it should be remembered that typological characterizations often reflect tendencies rather than absolute differences between languages" (Berman and Slobin 1994: 118), and it is not impossible to use the constructional approach to specify such typological "tendencies" in a more precise manner. Berthele (2013) has a much more radical proposal, arguing that any notion of language — distinct from actual language use - is reificational and thus that labels like "French," "English," or "Atsugewi" actually refer to bundles of regionally, sociologically, and stylistically stratified usage patterns. On this take, researchers should rather pay attention to the variability within each spatial semantic category across language varieties instead of focusing on either language types or implicational universals. One could argue that this is a rather extreme position and between it and that of "discrete" language types there is a space of possibilities that needs to be explored.

\subsection{Form classes beyond "verb" and "satellite?"}

Another way in which the initial typology has been found deficient is in the need to consider other form classes (i.e. lexical and grammatical, free and bound morphemes) that participate in the constructions that express motion events. The original duo of "verb" and "satellite" very soon turned out to be insufficient, or else the notion of "satellite" was extended beyond all proportion. Ever since it was first introduced by Talmy (1985: 102), the construct satellite has been contrasted with that of preposition (or adposition more generally) in straightforward grammatical terms: "any constituent other than a nominal or prepositional phrase complement that is in sister relation to the verb root" (Talmy 2000b: 222). For example, in the Swedish example (2) in ('in') is a verb-particle, which both by prosodic and syntactic criteria forms a constituent with the verb springa ('run'). On the other hand, the preposition $i$ ('in') clearly forms a prepositional phrase with rummet ('the room'). However, not all languages (or constructions) allow such a clear separation, including English, where the corresponding motion event sentence (7) appears to blend particle and preposition in a single form (into), at least in writing.

(7)

John ran into the room. 
Thus, in line with the binary nature of the original typology, some authors generalized the notion of satellite to any "more grammatical element such as preverb, particle or adposition" (Imbert 2012: 239) or even beyond that to adverbs, and just about anything else but verbs. ${ }^{3}$ Imbert defends such an obvious overgeneralization by arguing that Talmy had over the years used the notion of satellite ambiguously, that is:

in two different senses, which led to confusion and arguments over the clarity or even the 'usefulness' of the notion. He used the term 'satellite' to designate a type of construction (S-framed construction), and also to designate a type of surface element (such as preverbs or particles) (ibid.: 240).

If so, then such ambiguity is in need of resolution as it makes little sense to conflate verbal prefixes and particles, on the one hand, with adpositions and case markers that clearly form a constituent with the (Landmarkexpressing) noun phrase, on the other.

Considering a number of different form classes, Ibarretxe-Antuñano (2009) found considerable differences in the way the categories Path and Manner are expressed, based on data from Frog-stories in 20 different languages. Specifically, languages such as Basque that allow more elaborate Path encoding (with up to three "ground elements" (Landmarks) per clause, as in the English example in (8)) usually make use of prepositions, case-marking, and adverbial suffixes as well as deictic verbs such as come and go (which we analyze as expressing Direction rather than Path, see Section 3).

(8)

She ran out of the house (Source) to the neighbor (Goal) across the street (Middle).

While acknowledging the important role of verbs as the single obligatory lexical category that encodes Path or Manner components of motion, Beavers et al. (2010) emphasize the broad scope of lexical and grammatical resources in the specification of motion events, such as those mentioned above, including serialization as in (4-6), but also additional form classes like aspectual affixes, compounding, and ideophones. The latter are a very productive strategy for expressing Manner of motion in languages like Basque (Ibarretxe-Antuñano 2004) and Japanese (Slobin 2004) and are also present in Telugu (9) and Thai (10).

(9)

$\begin{array}{llllll}\text { abbaayi } & \text { adavi-loo- } k i & \text { daba dabaa } & \text { parigedutuu } & \text { vellaa-du } \\ \text { boy[NOM.SG] } & \text { forest-in-DAT } & \text { ideophone } & \text { run-PTCP } & \text { go.PST-AGR } & \text { (Telugu) }\end{array}$

'The boy went to the forest, running quickly.'

(10)

$\begin{array}{llllllll}\text { kràdòot } & \text { lon } & \text { tuum } & \text { lon } & \text { pay } & \text { nay } & \text { lamthaan } & \text { (Thai) } \\ \text { jump } & \text { stumble } & \text { ideophone } & \text { descend } & \text { go } & \text { in } & \text { creek } & \end{array}$

'(He/she) jumped stumbling down loudly into the creek.'

In sum, as the "database" of analyzed languages and constructions increased, more and more different kinds of form classes have been found to encode different elements of motion semantics. Schematically, we can group these into (a) verbal and ad-verbal forms (verbs, prefixes, particles, adverbs) and (b) nominal and ad-nominal (nouns, adpositions, case-markers), since one broad dimension in which languages may be expected to differ is in their relative preference of one or the other set of form classes (see Wälchli 2001), a hypothesis that we test with respect to Thai and Telugu in Section 4.3. Further, a class that does not fall in either of these groups is that of ideophones (Dingemanse 2012; Ibarretxe-Antuñano 2017).

\subsection{What are the "constituents" of a motion event?}

Finally, we come to the most serious problem with the Talmian model, since without clear definitions of the concepts that constitute a motion event - those that are expressed using various form classes (2.3) and constructions (2.2) across languages (2.1) - it becomes doubtful that any clear comparison can be made. There are many indications that such definitions have been lacking. For example, in the review article that we quoted earlier, Imbert (2012: 254) writes that:

[...] the notion of Path itself is not consensual; it has received different analyses and does not always cover the same scope: should it refer both to translocation and location, or just translocation? Should it incorporate other conceptual elements such as Deixis? 
The same can be said for all other categories as well. Starting from the most general, Talmy (2000b: 162) characterizes a Motion event as "a situation containing motion or the continuation of stationary location," thus underspecifying whether the denoted situation involves motion or not. This then is divided into four semantic elements: Motion, Figure, Ground, and Path, and in addition a "co-event" that most often specifies Manner or Cause of motion (or "locatedness," if the situation is static). Of these, only the notion of Figure (i.e. the entity that undergoes motion) has been unambiguous.

Motion is supposed to express the presence or absence of (actual) motion, and while the case of stasis is relatively clear, there are many different kinds of motion. Talmy made the difference between translational motion: "an object's basic location shifts from one point to another in space" and self-contained motion, where "an object keeps its basic or 'average' location" (Talmy 2000b: 35) and emphasized that the binary typology is concerned with motion only of the first kind. However, it has not been fully clear what this distinction amounts to and what is meant by "basic location," as there are persistent conflicting opinions on, for example, what kind of motion is involved in (11). In relation to the park as a whole, Mary does not change her basic location, but from the point of view of some imaginary observer, she does.

(11)

Mary is jogging in the park.

Further, Talmy juxtaposes the Gestalt psychological terms "figure" and "ground." While in the case of the first his use of the term is appropriate, this is hardly the case with respect to the latter, which in Gestalt psychological terms is to be an un-differentiated background for the standing-out figure (e.g. Wagemans et al. 2012). While this may be the case for the park in (11), the noun-phrases in, for example, (8) specify source, goal, and middle "semantic roles" that do not serve as background, but rather as a secondary focus of attention. For this reason, it is more reasonable to refer to them as landmarks, following the terminology of Langacker (1987) and Regier (1996).

But relating a Figure to one or more Landmarks is in most cases not sufficient to specify its location or translocation. As emphasized by Jackendoff (1992), a semantic category (or "function") is needed to express a Region in relation to the Landmark entities. In (12) the prepositions over and under accomplish this, helping to express very different kinds of translocations: the motion event in (12a) takes place on top of the bridge, while that in (12b), in the space below the bridge. In addition, the figure in (12a) is in contact with the bridge, moving along its length, while in (12b), it (most likely) moves in a perpendicular trajectory. This additional semantic information is not coded explicitly, but rather inferred from the pragmatic knowledge of a plane flying under a bridge, as in an air-show. In other words, it is expressed covertly, in the terminology of HSS (see next section).

(12a)

The car drove over the bridge.

$(12 b)$

The plane flew under the bridge.

Further, as pointed out by Imbert (2012) in the citation above, the category Path - which is most central for the typology - has been rather unclear: should it cover static locatedness and motion without change of location (with respect to the overtly expressed Landmark) as in (11) as well as clear cases of translocation as in (12)? What about Deixis, treated often as a separate category (Matsumoto 2003), in part because it may be expressed in a separate "slot" alongside Path, not only in serial verb languages, as pointed out in Section 2.1, but also in many other languages like Japanese? In addition, sentences like (13) clearly express translocation, but do not relate this to any Landmark, but rather to a more general coordinate system - in this case involving the vertical dimension (see Zlatev 2007). Should they be subsumed under Path or not?

(13)

The balloon is going up.

Finally, the "co-event" notion of Manner understood as the specification of "how the figure is moving or located" (Imbert 2012: 237) has usually been left even vaguer in the literature. The vehicle of translocation, expressed in (12) through the verbs drive and fly, is only one possible "how" dimension, but there are many others: bodily movement (run vs. crawl), speed (hurry vs. walk slowly), general style (determined vs. relaxed), and the shape of movement (straight vs. zigzaging) (Ekström 2015). Slobin et al. (2014) specify some of the dimensions of Manner as far as human locomotion is concerned. 


\subsection{Summary}

This section has served the double function of providing a critical literature review and at the same time summarizing four main problems with the original binary typology of motion event expression. To recapitulate, the main topics of this debate have concerned: (a) languages that do not easily fit either the Spanish-like "verbframed" nor the English-like "satellite-framed" type; (b) extensive within-type and even within-language variation, leading to the proposal to formulate the typology on the level of constructions only; (c) the inclusion of other form classes such as prepositions, case-markers, sentential adverbs, and ideophones, which are not (easily coerced into being) "satellites" or "verbs;" and (d) conceptual issues in defining the relevant semantic categories such as Path, Manner, and even Motion itself. In the next section, we describe a theoretical framework that provides answers to these issues. We hasten to add that these are not the only possible answers and we will not engage in explicit comparison with other more recent frameworks in post-Talmian motion event typology (e.g. Bohnemeyer et al. 2007; Croft et al. 2010), which would be the topic of a separate paper.

\section{Holistic Spatial Semantics of motion events}

The theory of Holistic Spatial Semantics (Zlatev 1997, 2003, and 2007; Blomberg 2014; Fagard et al. 2013) was developed for the sake of exploring the semantic typology of location and translocation across languages and constructions, and to be able to address issues such as those reviewed in the previous section. Its name derives from the claim that the minimal unit of analysis in spatial semantics is the whole locative or translocative utterance, where the meaning of the parts is dependent on the whole and vice-versa. Focusing here on translocation, this can be defined as change of a figure's relative average position in a given frame of reference (Zlatev et al. 2010). As the utterance is the minimal independent move in a conversation and (trans)locative utterances function as replies to where-questions (Zlatev 1997), minimal translocative utterances are, e.g. Out, Down, and There, as they can serve as replies to a question like "where are you going?" The theory aims to strike a balance between universalism and linguistic and cultural diversity by proposing a number of general semantic categories based on pre-linguistic bodily experience, but conventionalized in language-specific ways both with respect to the values these categories assume (especially the Region and Manner categories, see below) and with respect to how they are expressed in individual languages. When capitalized, we refer to semantic categories that are sedimented upon the pre-linguistic, embodied ones (Zlatev and Blomberg 2016).

How does HSS address the issues presented in the previous section? Starting with the last question concerning the constituents of a motion event (see Section 2.4), the theory claims that the following seven semantic categories are necessary for the analysis of spatial semantics across the world's languages.

1. Figure (F): the focal entity that undergoes translocation.

2. Landmark (LM): one or more physical entities (expressed by nominals) in relation to which the translocation of the Figure may (but need not be) be specified.

3. Region (R): an area of space usually defined in relation to a Landmark.

4. Motion (M): perceivable actual motion; else the situation is stative.

5. Frame of Reference (FoR): following Levinson (2003), but generalizing to dynamic situations and the vertical plane (Zlatev 2007), there are three different kinds of FoRs:

(a) Object-centered (OC), defined through one or more Landmarks, as in (8), (11), and (12).

(b) Geocentric (GC), which involves relatively fixed ("absolute") reference points or axis, as expressed in (13).

(c) Viewpoint-centered (VC), as in (14a), covering the class of motion situations anchored at a deictic center.

6. Direction (D): a category expressing unbounded translocation can be defined, where the motion event is specified as a vector along one of the axes provided by a FoR, as shown in (14). Crucially, unlike the case of Path, there is no Landmark involved, as even in (14c), the relevant "object" is that of the Figure itself. 
(14b)

The car is going north.

(14c)

The car is moving backward.
FoR: Geocentric (GC)

FoR: OBJeCt-CENTERed (OC)

7. Path: this is limited to bounded translocation, where a Landmark and Region are recruited to specify the Beginning, Middle, and/or End of the translocation, as shown in (15). ${ }^{4}$ Thus, HSS defines the category Path similarly to that of Path-function (Jackendoff 1992) or Path-schema (Regier 1996) rather than as a fully specified trajectory (see Zlatev 2007). Also, unlike Talmy, and some earlier formulations of the HSS theory (Blomberg 2014; Zlatev 2003) we here limit the use of Path only to translocation (i.e. with change of relative average position of the Figure). So, if neither Direction nor Path is expressed (overtly or covertly) in a spatial utterance, it is to be treated as non-translocative even if there is Motion, as in (11). Conversely, a value for Path does not necessarily imply a positive value for Motion, as shown by (15d).

Bill went out of the room.

Path: Beginning; Motion +

(15b)

Bill went through the room.

Path: Middle; Motion +

(15c)

Bill went into the room.

Path: End; Motion +

(15d)

Bill is out of the room.

Path: End; Motion -

Concerning the ambiguities surrounding "translational motion" discussed in Section 2.4, we can note that our notion of translocation is unambiguous: if the utterance presents the Figure as changing its relative average position according to one of the three spatial Frames of Reference (i.e. OC, GC, VC), then it is translocative. All example sentences discussed so far express translocation, except in (11), where Mary is certainly in motion, but does not change her average position relative to the FoR that is overtly (explicitly) expressed by the park (OC). The reason that many people have the intuition that (11) nevertheless involves translocation is that when imagining the situation, one automatically construes a Viewpoint-based FoR, thus "seeing" Mary change her location relative to this. But note that such a VC FoR is by no means overtly expressed in (11); at most, we could say that it may be expressed covertly, given an appropriate context (e.g. indicating that Mary is moving away from or towards some implicit point of view)..$^{5}$

The seven categories listed above are necessary but not sufficient for the full characterization of a motion event. Consistent with Talmy's original approach (but without regarding these as expressing a "co-event"), the theory treats the following three categories as secondary, as their centrality differs across languages and constructions:

8. Manner: specifications of various aspects in the way motion is conducted, including: (a) bodily locomotion (jump); (b) vehicle (ride); (c) medium (sink); (d) velocity (rush); (e) attitude (mindfully); and possibly other kinds.

9. Shape: in contrast to Manner, this concerns the geometrical form of the trajectory of movement, especially prominent in signed languages (Ekström 2015).

10. Cause + Causation: respectively, the instigator or the movement, in cases where this is not the Figure itself, and the specification of the nature of the causal force (e.g. throw vs. kick). 
While the co-expression of Cause, Manner, and Shape in a single clause may not be common, (16) shows an example sentence from English where this is the case.

(16)

\begin{tabular}{|c|c|c|c|c|}
\hline $\begin{array}{l}\text { The explosion } \\
\text { Cause }\end{array}$ & $\begin{array}{l}\text { made } \\
\text { Causation }\end{array}$ & $\begin{array}{l}\text { the plane } \\
\text { Figure }\end{array}$ & $\begin{array}{l}\text { fall } \\
\text { Manner }\end{array}$ & $\begin{array}{l}\text { spiraling } \\
\text { Shape }\end{array}$ \\
\hline
\end{tabular}

A general prediction made by the model is that the primary and secondary semantic categories are necessary and jointly sufficient for the specification of the meaning of a motion event in any human language. Another prediction is that any translocative utterance will express (overtly, see below) at least one kind of Frame of Reference (i.e. OC, GC, or VC), and in many cases involves the combination of several. Both of these predictions have found support in previous work (Blomberg 2014).

How are these semantic categories predicted to be expressed? The theory is intentionally left open in this respect in order to address the issue discussed in Section 2.3. The only a priori assumptions are that Motion is to be expressed by the (main) verb and Landmark by a nominal. Given these form classes that are close to universal (Croft 2003) it is up to each language to develop its inventory of form classes participating in the expression of spatial semantics through processes of grammaticalization (Heine and Kuteva 2007). As mentioned in Section 2.3, some of these form classes are adverbial (the so-called "satellites"), other are adnominal, such as adpositions and case-markers, and third are neither, like spatial deictics and ideophones.

The theory explicitly predicts a many-to-many mapping between the semantic categories listed above and such form classes. This subsumes Talmy's (1985) proposal about patterns in which one form class conflates more than one semantic category, as well as the converse mapping in which a single semantic category is distributed (Sinha and Kuteva 1995) across several classes. The Swedish example in (2) is given again in (17) as instantiating a self-caused, translocative motion construction where two cases of conflation (Motion + Manner $=\mathrm{V}$ and Path + Region $=$ PRT) and one case of distribution $\left(\right.$ Region $=$ PRT + PREP) are present. ${ }^{6}$ The third pattern is systematic composition of different categories expressed in different form classes (Motion $=\mathrm{V}$, Region $=$ Prep).

(17)

$\begin{array}{lllll}\text { Sven } & \text { sprang } & \text { in } & i & \text { rumm-et } \\ \text { Sven } & \text { run.PST } & \text { in } & \text { in } & \text { room-DEF } \\ \text { NP } & \text { V } & \text { PRT } & \text { PREP } & \text { NP } \\ \text { Figure } & \text { Motion } & \text { Path } & \text { Region:In } & \text { LM } \\ & \text { Manner } & \text { Region:In } & & \end{array}$

'Sven ran into the room.'

This many-to-many mapping between meaning and form is a natural consequence of the kind of meaningholism predicted by the theory (Zlatev 1997). On the one hand, the meaning of the translocative utterance as a whole will be a combination of the expressions of the central categories Figure, Path, Direction, Region, Landmark, Motion, and FoR, each one of which is potentially distributed. But at the same time, the meaning of the whole utterance constrains the interpretation of individual expressions and their semantic values. For example, if went is substituted with walked and room with woods in (15b), the preferred interpretation will be non-translocative, analogous to (11).

Another aspect of meaning holism is covert expression. In the French example (18), there is no explicit expression of Path (unlike in the English translation with into) but it may nevertheless be inferred (pragmatically) given appropriate context: if we know that Marie had just heard a loud noise from inside, the preferred interpretation of native speakers is that she translocated into the room, rather than ran around inside it.

(18)

$\begin{array}{llllll}\text { Marie } & a & \text { couru } & \text { dans } & \text { la cuisine } & \text { (French) } \\ \text { Marie } & \text { AUX } & \text { Manner } & \text { Region } & \text { Landmark } & \\ \text { Figure } \\ \text { Covert expression: }\end{array}$

'Marie ran into the room.'

What does the theory state concerning the issues of motion event language types? Early empirical research using HSS (Zlatev 1997) documented different constructions of overt and covert expression across eight different languages: Swedish and English (Germanic), Bulgarian and Serbian (Slavonic), Italian and Spanish (Romance), and Finnish and Estonian (Finno-Ugric), with the languages clustering according to the four genealogical types, with the Slavonic and Finno-Ugric languages being in no obvious way more similar to the Germanic 
than to the Romance. Further work showed that Thai, with its productive use of serial-verb constructions, appeared different from these Indo-European and Finno-Ugric languages (Zlatev 2003). But as these studies were not based on a systematic elicitation procedure, it was difficult to provide a clear account of the similarities and differences across languages and constructions.

A more systematic study using HSS was therefore performed by Blomberg (2014), who presented a series of video-clips to speakers of Swedish, French, and Thai, coding these for the semantic categories and their mappings to form classes. The main findings were that descriptions of the motion events in the three languages indeed seemed to cluster according to the types proposed by Slobin's three-way typology: Swedish speakers made heavy use of Manner verbs and Path particles, French speakers regularly used Path and Direction verbs, and the Thai speakers used serial-verb constructions, stringing Manner, Path, and Direction verbs. At the same time, there were construction-specific patterns. For example, in vertical motion situations and corresponding constructions (e.g. jumping down), French speakers regularly used Manner verbs. Actually, Blomberg found a greater number of different kinds of Manner-verbs in the French data than in the Swedish speakers, showing that issues of type and token frequency need to be distinguished.

In another typological study, Fagard et al. (2013) combined some of the data of Blomberg (2014) with elicited descriptions from the Italian regional language Piedmontese, German, and Polish. The results showed that Thai was similar to German and Swedish in allowing composite Paths with multiple Landmarks, consistent with an alternative language typology based on the number of "ground elements" (i.e. landmarks) per clause (Bohnemeyer et al. 2007). In terms of the frequency of Path expression, German surprisingly aligned with the two Romance languages while Swedish, Thai, and Polish clustered together. With respect to Direction (VC), the Thai participants used deictic verbs more frequently than the speakers of the other languages. German and Swedish participants, especially in describing "boundary-crossing" scenes, were not far behind, while French and Piedmontese speakers used very few deictic verbs in boundary-crossing contexts and Polish speakers did not mark deixis at all. Thus, the six languages did not cluster along a two or three-way typology, but formed criss-crossing patterns, depending on which criteria for comparison were used.

The implication of these findings is that it is not possible to give a conclusive answer to the question of "how many language types" (in motion event expression) without exploring a sufficiently large number of languages using a combination of qualitative and quantitative analysis, all based on naturalistic data and a clearly defined theoretical framework. As HSS provides the latter, and earlier work has successfully established parameters along which languages may either differ or cluster together, the only way to answer the question is by extending research to languages with genealogical and areal features that have not yet been analyzed. In the following section, we report on such a study of the Dravidian language Telugu, in comparison with a language that has already been explored with the HSS framework, Thai.

\section{HSS analysis of motion events in Thai and Telugu}

What first motivated our comparative study of the expression of motion events in Telugu and Thai was the observation that, despite considerable genealogical and typological differences, the two appeared to have some similarities (Zlatev et al. 2015). While both languages may conflate Path and Motion in the verb, both also allow the use of Manner verbs in boundary-crossing situations, as shown in (1) and (4). Further, both may use ideophones, as in (9) and (10), to express one or another dimension of Manner. Telugu may be expected to mark Path through case-marking, as in (1), but Thai also has prepositions like caàk ('from') and thuǔn ('up to'), grammaticalized from verbs (Intrarat 1996), that may be seen as analogous with the Telugu cases. Finally, as described in Section 2.1, Thai has been suggested to belong to a possible "third type," and if Telugu could be shown to pattern together with Thai, then perhaps the original typology could simply be extended from a binary to a three-part typology, as proposed by Slobin (2004). The results of the study, however, showed otherwise, as we document below.

\subsection{Methods}

We used data originally collected within earlier projects for the study. ${ }^{7}$ The data was gathered with the help of one of the "classic" elicitation methods in the field: narrations based on the 24-page wordless picture book Frog, Where Are You? (Mayer 1969). While this method of elicitation has well-known disadvantages - the motion situations are depicted in static pictures and the events need to be inferred rather than perceived, and the way the story is parsed page by page affects the way the events are described - there are also some advantages compared to using individual video-clips as elicitations. In particular, the event descriptions are organized in stories, which is arguably a more natural mode of language use than that of providing independent event 
descriptions. Also, there is a rich database of comparable data for the sake of developmental and typological studies (Berman and Slobin 1994; Strömqvist and Verhoeven 2004). On the other hand, nearly all motion events in the story involve self-motion, as opposed to caused motion. Hence, while the HSS framework may be applied to both kinds of motion events, we limited our study to self-motion, i.e. where the Figure is the instigator of the translocation.

The participants in the study were 10 native speakers of Telugu living in Hyderabad (mean age, 22.4, 7 female) and 10 speakers of Thai living in Bangkok (mean age 22.1, 5 female). The instructions given to both groups were to first familiarize themselves with the story in the book by looking though the 24 pictures (the Telugu group did this on a computer monitor, while the Thai participants used a paper-book copy). Then they were asked to go back to the first page and "tell the story" to the experimenter, as they turned the pages in their own pace. These narrations were audio-recorded, transcribed, and analyzed. ${ }^{8}$

The narratives were segmented by pictures -24 descriptions for each narrative with one or more clauses per description. Table 1 shows the size of the corpus. As can be seen, the narratives of the Thai participants were almost three times longer in terms of both clauses and word tokens. However, if we compare only the self-motion event descriptions in the two sets of narratives, the differences in size between the Thai and Telugu data become relatively smaller. ${ }^{9}$

Table 1: The "Frog stories" of 10 Thai and 10 Telugu speakers, analyzed for total number of clauses and word tokens as well as specifically for motion event descriptions.

\begin{tabular}{lllll}
\hline Group & $\begin{array}{l}\text { In total } \\
\text { Clauses }\end{array}$ & Word-tokens & $\begin{array}{l}\text { Self-motion event descriptions } \\
\text { Clauses }\end{array}$ & Word-tokens \\
\hline Thai & 1235 & 8144 & 406 & 3699 \\
Telugu & 431 & 3221 & 291 & 2563 \\
\hline
\end{tabular}

The data was exported to Excel and coded for the following HSS semantic categories (see Section 3): Path (with values for Beginning, Middle, and End), Direction (with Geocentric, Viewpoint, and Object-centered FoR), Region (with values for Inside, Outside, Above, Below, Near, Side, etc.), Landmark (with the specific objects like Bottle, Cliff, and Forest expressed by noun phrases, including anaphoric and cataphoric references), and Manner (including aspects such as Locomotion, Vehicle, Speed, etc.) In coding, it was also specified how these categories were expressed by which form-classes, allowing for conflation and distribution. The following form classes turned out to be sufficient for the two languages: verb, noun, preposition, case-marker, adverb, and ideophone.

On this basis, we performed a qualitative analysis, focusing on the most common constructions expressing the different semantic categories (4.2) and a quantitative analysis, comparing the types and tokens of the form classes expressing these categories in each language (4.3).

\subsection{Qualitative analysis}

Here, we present the main construction types for expressing the most relevant motion semantic categories: Path, Region, Landmark, Direction (with different FoR), and Manner. All examples that were attested in the data are marked with the code (Language_ParticipantCode_SceneNumber). In addition, we provide some examples of ungrammatical sentences on the basis of native-speaker intuitions. In Section 4.2.5, we offer some generalizations, focusing on similarities and differences in the motion-expressing constructions in the two languages. We should note here the limitations of the method: as with any analysis based on actually attested data and particular stimuli, this cannot be considered as fully representative for the languages in question. To help keep this in mind, we use the past tense in describing the examples and patterns that were attested, using the present tense only when we (with care) venture into what is allowed by the norms of the languages or language varieties in question.

\subsubsection{Path}

The expression of Path was distributed in the Telugu data over two form classes: case markers and verbs, as in (19). However, it was also expressed only by a case-marker, as in (22). The relevant case markers are the Ablative (numci 'from') and the Dative (-ki/-ku 'to'), which express Path:Begin and Path:End respectively. As can be seen in (19), the dative case marker - $k u$ may combine with the verb ceerukonu 'arrive' to express Path with the identical value (End). 
(19)

\begin{tabular}{|c|c|c|c|c|c|}
\hline $\begin{array}{l}\text { kukkaa } \\
\operatorname{dog} \text { [NOM.SG] }\end{array}$ & $\begin{array}{l}\text { baabuu } \\
\text { boy[NOM.SG] }\end{array}$ & $\begin{array}{l}\text { iddaru } \\
\text { both }\end{array}$ & $\begin{array}{l}\text { kalisi } \\
\text { together }\end{array}$ & $\begin{array}{l}\text { oddu-ku } \\
\text { shore-DAT }\end{array}$ & $\begin{array}{l}\text { ceerukunnaa-ru } \\
\text { arrive.PST- } \\
\text { AGR }\end{array}$ \\
\hline $\mathrm{N}$ & $\mathrm{N}$ & & & N-Case & $\mathrm{V}$ \\
\hline $\begin{array}{l}\text { Figure } \\
\text { 'The dog and } t \text { l }\end{array}$ & oov reached the & & & LM-Path:End & $\begin{array}{l}\text { Motion + } \\
\text { Path:End } \\
\text { (Tel_6_19) }\end{array}$ \\
\hline
\end{tabular}

If Path is expressed both in the verb and through case - and the corresponding value is not the same, as when the verb daatu 'cross' (expressing Path:Middle) combines with $k u$ (Path:End) - the result is a semantic clash, rendering the sentence ungrammatical, as in the invented example (20).

(20)

$\begin{array}{lll}{ }^{*} \text { baabuu } & \text { moddu- } k u & \text { daateeśx- } d u \\ \text { boy[NOM.SG] } & \text { log-to } & \text { cross.PST-AGR } \\ \mathrm{N} & \text { N-case } & \text { V } \\ \text { Figure } & \text { LM-Path:End } & \text { Motion+ } \\ & & \text { Path:Middle }\end{array}$

'The boy crossed to the log.'

The Thai speakers displayed a similar strategy, expressing Path either only through verbs like Pjok ('exit') (typically within a serial verb construction), together with the Path:Begin preposition càak ('from'), as shown in (21), or the Path:End preposition thǔn ('up to'), grammaticalized from the verb thuǔn ('reach').

\begin{tabular}{|c|c|c|c|c|c|c|c|}
\hline câw & fókkii & kamlay & jôy & P̉̀ok & maa & càak & khùat \\
\hline Mr. & Frog & PROG & tiptoe & exit & come & from & bottle \\
\hline $\mathrm{N}$ & $\mathrm{N}$ & & V & $\mathrm{V}$ & V & Prep & $\mathrm{N}$ \\
\hline & & & Motion & Motion & Motion & Path:Begin & \\
\hline & & & Manner & $\begin{array}{l}\text { Path:Begin } \\
\text { Region:In }\end{array}$ & Dir:VC & & \\
\hline
\end{tabular}

'Mr Frog was tip-toing out of the bottle.'

(Thai_1_2)

As can be seen in (21), Thai Path verbs like Pjok ('exit') conflate Motion, Path, and Region (Zlatev 2003; Blomberg 2014). However, there is also a form class dedicated to the expression of Region in both languages, as we show below.

\subsubsection{Region and Landmark}

To remind, the category Region specifies an area of space, typically in relation to a Landmark, where the Figure is located or through which it moves. In Telugu, this is expressed by a form class variously known as "nominal adverbs," "adverbial nouns," or "nouns of space and time" (Krishnamurti and Gwynn 1985), with expressions like loo(pala) ('in[side]'), bayata ('out'), kimda ('below'), and pai /paina ('above'). In Thai, the corresponding formclass has been treated either as "relator nouns" (Indrambarya 1995) or as prepositions (Panupong 1989). For both languages, the ambiguity in the terminology reflects the rather ambiguous grammatical status of the class. In Telugu, the (originally) nominal status of the class is indicated by the fact that these Region expressions can be marked with the Path case markers -ki (Dative) and numci (Ablative), just as "ordinary" nouns, as shown in (22).

$(22)$

$\begin{array}{llllll}\text { oka cinna ramd ram } & \text { loo-numci } & \text { eluka } & \text { bayati-ki } & \text { vacci } & \text { cuusim-di } \\ \text { one small hole } & \text { in-ABL } & \text { rat[NOM.SG] } & \text { out-DAT } & \text { come.PTCP } & \text { see.PST-AGR } \\ \text { NP } & \text { N-Case } & \text { N } & \text { N-Case } & \text { V.PTCP } & \text { V } \\ \text { LM } & \text { Region:In } & \text { Figure } & \text { Region:Out } & \text { Motion } & \\ & \text { Path:Begin } & & \text { Path:End } & \text { Direction:VC }\end{array}$

'A rat looked out, coming out of a hole in the ground.'

(Tel_5_10) 
In example (22), the Landmark expression oka cinna ramd ram ('one small hole') is what helps specify the exact areas indicated by the two Region expressions: the inside and outside of the hole. But it is also possible to omit the Landmark if it is understood from the context, as in (23), ${ }^{10}$ or to express it through an anaphoric pronoun like daani ('it'), in this case co-referential with moddu (' $\log ^{\prime}$ ) in (24), which notably lacks a finite verb.

(23)

$\begin{array}{lll}\text { iddaruu } & \text { bayati-ki } & \text { vastaa-ru } \\ \text { both[NOM.SG] } & \text { out-DAT } & \text { come.PST-AGR } \\ \text { Pron } & \text { N-Case } & \text { V } \\ \text { Figure } & \text { Region:Out } & \text { Motion } \\ & \text { Path:End } & \text { Direction:VC } \\ \text { 'Both came out.' } & & \text { (Tel_2_19) }\end{array}$

(24)

$\begin{array}{llllll}\text { baabuu } & \text { imkaa } & \text { kukkaa } & \text { daani } & \text { pai-ki } & \text { ekki } \\ \text { boy[NOM.SG] } & \text { also } & \text { dog[NOM.SG] } & \text { it.ACC } & \text { above-DAT } & \text { ascend.PTCP } \\ \text { N } & \text { Adv } & \text { N } & \text { Pron } & \text { N-Case } & \text { V } \\ \text { Figure } & \text { Figure } & \text { LM } & \text { Region:Above } & \text { Motion } \\ & & & \text { Path:End } & \text { Direction:GC } \\ & & & \text { Manner } \\ \text { (Thel_4_23) }\end{array}$

Concerning Thai, Prasithrathsint (2010) provides an illuminating analysis of the grammatical status of Region expressions, showing that the older, less grammaticalized noun forms co-exist with the more grammaticalized prepositional forms, and how it is possible to distinguish between the two using constructional criteria. In (25), for example, it is not possible to insert the possessive marker khoon ('of') between nuua ('above') and the subsequent Landmark expression, nor to omit the latter, indicating that here we have a clear case of prepositional usage.

$\begin{array}{lllllll}\text { piituîu } & \text { k̂ } & \text { piin } & \text { khuîn } & \text { maa } & \text { nǔa } & \text { khòot+ȟn } \\ \text { Peter } & \text { well } & \text { climb } & \text { ascend } & \text { come } & \text { above } & \text { rock } \\ \mathrm{N} & \text { Prt } & \mathrm{V} & \mathrm{V} & \mathrm{V} & \text { Prep } & \text { NP } \\ \text { Figure } & & \text { Motion } & \text { Motion } & \text { Motion } & \text { Region:Above } & \text { LM } \\ & & \text { Manner } & \text { Dir:GC } & \text { Dir:VC } & & \end{array}$

'Peter climbed up (towards us) to the top of the rock.'

(Thai_1_14)

However, when the grammaticalized forms are preceded by one of a small class of expressions: khây, dân, phaay ('side'); or buîn, thaan ('direction'), the result is a compound noun, as in the case with khây+nôsk ('outside') in (26). In this case, a Landmark is not needed, but may appear optionally — in that case, making the compound noun function as a complex preposition (Prasithrathsint 2010).

(26)

\begin{tabular}{|c|c|c|c|c|c|c|}
\hline $\begin{array}{l}\text { câw } \\
\text { Mr. }\end{array}$ & $\begin{array}{l}k o ̀ p \\
\text { frog }\end{array}$ & $\begin{array}{l}\text { nósy } \\
\text { small }\end{array}$ & $\begin{array}{l}\text { Pàtcà } \\
\text { perhaps }\end{array}$ & $\begin{array}{l}\text { kràdòot } \\
\text { jump }\end{array}$ & $\begin{array}{l}\text { pay } \\
\text { go }\end{array}$ & $\begin{array}{l}\text { khây+nôok } \\
\text { outside }\end{array}$ \\
\hline $\mathrm{N}$ & $\mathrm{N}^{\circ}$ & $\mathrm{ADJ}$ & ADJ & $\mathrm{V}$ & $\mathrm{V}$ & $\mathrm{NP}$ \\
\hline Figure & & & & $\begin{array}{l}\text { Motion } \\
\text { Manner }\end{array}$ & $\begin{array}{l}\text { Motion } \\
\text { Direction:VC }\end{array}$ & Region:Out \\
\hline
\end{tabular}

\subsubsection{Direction}

It may need to be reminded that HSS makes a systematic distinction between Path (which always expresses bounded motion, delimited by a Landmark) and Direction, which is not defined with respect to a Landmark, but rather represents one of three kinds of unbounded motion depending on the respective Frame of Reference (FoR): Viewpoint-Centered (VC), Geocentric (GC), and Object-Centered (OC). 
VC Direction was expressed in the Telugu data with the verbs vaccu ('come') and vellu or poovu ('go') as shown in (22-23). GC Direction is expressed by means of the verbs ekku ('ascend'), as shown in (27), and digu ('descend'). ${ }^{11}$

(27)

$\begin{array}{lll}\text { banda } & \text { pai-ki } & e k k a a-d u \\ \text { stone } & \text { above-DAT } & \text { ascend.PST-AGR } \\ \mathrm{N} & \text { N-Case } & \text { V } \\ \mathrm{LM} & \text { Region:Above } & \text { Motion } \\ & \text { Path:End } & \text { Direction:GC } \\ & & \text { Manner }\end{array}$

'(He) ascended the boulder nearby.'

(Tel_6_14)

Unless one of these two kinds of Direction expressions is in participle form, they cannot be combined in a single clause in Telugu. Such combinations were, on the other hand, commonplace in the serial-verb constructions used by the Thai speakers. Example (28) combines two values of Direction (GC+VC), Path, specified for the value Begin in the preposition càak, but also for the value End, conflated together with Manner (effort) in the verb phlò ('emerge').

(28)

$\begin{array}{lllllll}k \hat{s} & \text { phlòo } & \text { khuîn } & \text { maa } & \text { càak } & \text { náam } & \text { dây } \\ \text { well } & \text { emerge } & \text { ascend } & \text { come } & \text { from } & \text { water } & \text { able } \\ \text { Prt } & \text { V } & \text { V } & \text { V } & \text { Prep } & \text { N } & \text { V } \\ & \text { Motion } & \text { Motion } & \text { Motion } & \text { Path:Beg } & \text { LM } & \\ & \text { Path:End } & \text { Dir:GC } & \text { Dir:VC } & & & \\ & \text { Manner } & & & & & \end{array}$

'(He) could pop up from the water.'

(Thai_7_19)

In the case of Object-centered (OC) Direction, as noted in Section 3, this needs to be specified with respect to the Figure (e.g. forward). In Telugu, it is possible to express OC-Direction by marking a Region-expressing noun with the Dative case marker, as is the case with pakka-ku ('sideways') in (29).

(29)

\begin{tabular}{|c|c|c|c|c|}
\hline $\begin{array}{l}\text { baabu } \\
\text { boy }\end{array}$ & {$[\ldots]$} & $\begin{array}{l}\text { bayapadi } \\
\text { frighten.PTCP }\end{array}$ & $\begin{array}{l}\text { pakka-ku } \\
\text { side-to }\end{array}$ & $\begin{array}{l}\text { vastaa- } d u \\
\text { come.PST-AGR }\end{array}$ \\
\hline $\mathrm{N}$ & & V & $\mathrm{N}$-case & $\mathrm{V}$ \\
\hline Figure & & Manner & $\begin{array}{l}\text { Dir:OC } \\
\text { Region:Side }\end{array}$ & Motion+ Dir:VC \\
\hline
\end{tabular}

'The boy moved aside in fright.'

(Telugu_1_10)

Thai allows OC-Direction to be expressed in a similar way, as in (30), combining a deictic verb with a compound noun of the kind described earlier: one of the expressions khây, dân, phaay ('side') and buîay, thaan ('direction') combines with one of the Region expressions nâa ('face, front') or lăy ('back, behind'). However, there were no such instances in the data.

(30)

\begin{tabular}{|c|c|c|c|c|c|}
\hline malii & maa & pay & khân+nâa & l & khân+lăn \\
\hline Malee & go & come & side+front & / & side+back \\
\hline & $\mathrm{V}$ & & NP & & \\
\hline Figure & Motion & & & & \\
\hline & Direction:VC & & $\begin{array}{l}\text { Direction:OC } \\
\text { Region:Front }\end{array}$ & 1 & $\begin{array}{l}\text { Direction:OC } \\
\text { Region:Back }\end{array}$ \\
\hline
\end{tabular}

'Malee went/came forward/backward.'

\subsubsection{Manner}

The Thai examples shown so far have featured several Manner verbs, such as jôn ('tiptoe'), kràdòot ('jump'), piin ('climb'), and, shown in (28), the Manner+ Path verb phlò ('emerge'). The observant reader would have 
noticed a stable pattern (see Zlatev and Yangklang 2004; Kessalul 2005): Manner is always expressed first in the verb series, followed by Path and/or GC-Direction, and finished by VC-Direction. ${ }^{12}$ Thus, the alternative permutations of the correct order from example (25) shown in (31) are all ungrammatical if considered as single clauses. ${ }^{13}$

(31)

$\begin{array}{llll}\text { a. } & { }^{*} \text { khûn } & \text { piin } & \text { maa } \\ \text { b. } & { }^{*} \text { maa } & \text { khuin } & \text { piin } \\ \text { c. } & { }^{*} \text { piin } & \text { maa } & \text { khuûn } \\ \text { d. } & { }^{*} \text { khûn } & \text { maa } & \text { piin } \\ \text { e. } & { }^{*} \text { maa } & \text { piin } & \text { khû̂n }\end{array}$

In being an agglutinative language (Subrahmanyam 1971; Zvelebil 1977) that marks tense on the verb, Telugu may have only one main, tensed (finite) verb per clause. When this is a Manner-expressing verb, as duuku ('jump') in (32), there is no difficulty in expressing a boundary-crossing Path.

(32)

$\begin{array}{lll}\text { kitikii } & \text { loo-nuncii } & \text { duukeesim-di } \\ \text { window } & \text { inside-ABL } & \text { jump.PST-AGR } \\ \mathrm{N} & \text { N-case } & \text { V } \\ \text { LM } & \text { Region:In + } & \text { Motion + Manner } \\ & \text { Path:Begin } & \\ \text { '(It) jumped out of the window.' } & \text { (Tel_4_6) }\end{array}$

But it is also possible to express Manner in non-finite, participle forms of the verb in Telugu (with or without reduplication), together with a main verb expressing some other category such as Cause, as in (33), one of the few such cases in our data forcing us to limit the investigation to self-motion, as noted in the onset of this section.

(33)

\begin{tabular}{|c|c|c|c|c|c|c|}
\hline $\begin{array}{l}a a \\
\text { that }\end{array}$ & $\begin{array}{l}\text { jimka } \\
\text { deer[NOM.SG] }\end{array}$ & $\begin{array}{l}\text { parigettutuu } \\
\text { run.PTCP }\end{array}$ & $\begin{array}{l}\text { parigettutuu } \\
\text { run.PTCP }\end{array}$ & $\begin{array}{l}\text { baabu-ni } \\
\text { boy-ACC }\end{array}$ & $\begin{array}{l}\text { kimda } \\
\text { below }\end{array}$ & $\begin{array}{l}\text { padeestum-di } \\
\text { fall.CAUS.PST- } \\
\text { AGR }\end{array}$ \\
\hline \multirow{3}{*}{ Dem } & $\mathrm{N}$ & V & V & $\mathrm{N}$ & $\mathrm{N}$ & $\mathrm{V}$ \\
\hline & Agent & Motion & Motion & Figure & Region: Below & Motion \\
\hline & & Manner & Manner & & & $\begin{array}{l}\text { Direction:VC } \\
\text { Cause } \\
\text { Manner }\end{array}$ \\
\hline
\end{tabular}

As mentioned, both Thai and Telugu employ other linguistic resources, including adverbs and ideophones to express Manner. In (34), Manner is conveyed through the ideophone gaba gaba and the adverb hataattugaa ('suddenly') in (35). The Thai example (36) combines both form classes as well as the verb wîn ('run') in a highly distributed expression of Manner.

(34)

$\begin{array}{lllll}\text { kimda } & \text { padi-poogaanee } & \text { gaba gabaa } & \text { abbaayi } & \text { wacci } \\ \text { below } & \text { fall.PTCP-PRF } & \text { quickly } & \text { boy[NOM.SG] } & \text { come.PTCP } \\ \mathrm{N} & \mathrm{V} & \text { Ideophone } & \mathrm{N} & \text { V } \\ \text { Region:Below } & \text { Motion + Direction:VC } & \text { Manner } & \text { Figure } & \text { Motion + Direction:VC } \\ \text { 'The boy suddenly coming after (seeing the dog) fallen.' } & & \end{array}$

(35)

$\begin{array}{lllll}\text { akkadi-numci } & \text { hataattugaa } & \text { gudlaguuba } & \text { bayati-ki } & \text { raavadamtoo } \\ \text { there-ABL } & \text { suddenly } & \text { owl[NOM.SG] } & \text { out-DAT } & \text { coming } \\ \text { Pron-Case } & \text { Adv } & \text { N } & \text { N-Case } & \text { N.Gerund } \\ \text { LM-Path:Beg } & \text { Manner } & \text { Figure } & \text { Region:Out } & \text { Motion }+ \\ & & & & \text { Direction:VC }\end{array}$

'The owl suddenly coming out (from there).'

Path:End

(Tel_6_12) 
(36)

\begin{tabular}{lllll} 
dík & wîn & dûay & khwaam+rew & fùpfùpfùpfùpfùpfùp \\
Dick & run & by & speed & "like this" \\
N & V & & N & Ideophone \\
& Motion & & & \\
\multicolumn{1}{rl}{ Manner } & & Manner & Manner \\
'Dik ran very rapidly.' & & & (Thai_7_12)
\end{tabular}

\subsubsection{Summary}

The analysis offered in this section showed that the preliminary indications for some typological motion event similarities between Thai and Telugu (Zlatev et al. 2015) were to some extent confirmed. At the same time, some important differences transpired as well, serving as a counter-point to each similarity.

First, neither Thai nor Telugu possess any "satellite" form-class to express Path, given that we keep to the original definition covering verb-particles and prefixes separate from adnominal form classes like prepositions and case-markers. Rather, both languages allow the combination of verbal and (ad)nominal expressions of Path in the same clause. However, and to anticipate the analysis in the next section, while the most productive strategy for Path-expression in Thai seems to be verbal, as in (21), in Telugu this appears to be one of casemarking, i.e. an adnominal strategy as in (19) and (20).

Second, both languages have a dedicated form-class for the expression of the category Region, though this functions predominantly as a preposition in Thai, as in (25) - unless combined with an expression meaning 'side/direction' to form a nominal compound, as in (26) - and as a noun (or pronoun) in Telugu, capable of taking case-marking, as in (22-24).

Third, both languages express Viewpoint/Deictic ("come") and GC ("ascend") Direction through verbs, while they express OC Direction through Region nouns. A difference is that Thai allows the combination of several Direction expressions more easily, as in (28), while Telugu must specify a main verb, marking any additional verbs as participles as in (24).

Fourth, both languages may code Manner with verbs (irrespective of whether a boundary is crossed) and through ideophones and adverbs. However, again, Thai allows combining several of these form classes in the same clause, as in (36). Further, it allows for combining Manner with Path and Direction, and for distributing Motion in serial-verb constructions, as in (21) - unlike Telugu, which is more constrained in this respect. If the main verb codes Manner in a participle, Path (or Direction) can be coded in the main verb, as in (33). In principle, it also possible to combine Manner using a participle, Path through case-marking, and Direction in the main verb, but such a complex strategy was not attested.

Finally, Thai often conflates Path and Region in verbs with meanings like "exit" and "enter," while Telugu has a limited number of such verbs. Instead, it uses a compositional strategy, coding Path in the verb and casemarker and Region in the noun.

These generalizations are summarized on the basis of attested expression patterns in Table 2, showing patterns that are identical (assuming case and preposition-marking to be the same) in bold face. As can be seen, the majority of the patterns can be shown to be distinct.

Table 2: The three kinds of expression patterns in HSS: (a) semantic distribution (one category = more than one formclass); (b) conflation (more than one category = one form class); and (c) composition (one category = one form class), represented in the data from Thai and Telugu.

\begin{tabular}{|c|c|c|}
\hline Expression patterns & Thai & Telugu \\
\hline \multirow{4}{*}{ Distribution } & Path $=$ Verb + Prep & Path $=$ Case + Case \\
\hline & Motion $=\mathrm{V}+\mathrm{V}+\mathrm{V}$ & Path $=$ Case + V \\
\hline & Direction $=\mathrm{V}+\mathrm{V}$ & Region $=\mathrm{N}+\mathrm{N}$ \\
\hline & Direction $=\mathrm{V}+$ Compound $\mathrm{N}$ & \\
\hline \multirow{7}{*}{ Conflation } & Manner $=\mathrm{V}+$ Adverb & \\
\hline & Manner $=\mathrm{V}+$ Adverb + Ideophone & \\
\hline & Motion + Path $=\mathrm{V}$ & Motion + Path $=$ V \\
\hline & Motion + Direction $=\mathrm{V}$ & Motion + Direction $=\mathrm{V}$ \\
\hline & Motion + Manner $=\mathrm{V}$ & Motion + Manner $=\mathrm{V}$ \\
\hline & Motion + Path + Region $=V$ & \\
\hline & $\begin{array}{l}\text { Motion }=\text { V, Path }=\text { Prep } \\
\text { Region }=\text { NP, Manner = V }\end{array}$ & $\begin{array}{l}\text { Motion }=\text { V, Path }=\text { Case } \\
\text { Region }=\text { N, Manner }=\text { V }\end{array}$ \\
\hline
\end{tabular}

Composition 
Region $=$ NP, Direction $=\mathrm{V}$

Path $=$ V, Region $=$ Prep

Manner $=V$, Region $=$ Prep

Direction $=V$, Region $=$ Prep

Motion $=\mathrm{V}$, Region $=\mathrm{NP}$

Path $=$ V, Manner $=$ V, Dir $=$ V
Region $=$ N, Direction $=$ V

Path $=$ Case, Direction $=\mathrm{V}$

Path $=$ Case, Region $=\mathrm{N}$

Direction $=\mathrm{V}$,

Manner = Ideophone

Path $=$ Case

Manner $=$ Adverb

In sum, the qualitative analysis showed some similarities in the expression of motion events in the data from Thai and Telugu, but the differences between the languages were significant. With its salient feature of using serial-verbs, Thai is capable of "stacking" Manner, Path, and Direction expressions with ease, while Telugu speakers are forced to code one of these with the main (finite) verb, expressing the others through participles and case-marking (in the case of Path). Being a language with rich agglutinative morphology, Telugu rather anchors the motion descriptions around nominals, either specific Landmark expression or more general Region nouns, and their case-marking. In the following sub-section, we provide a quantitative analysis that makes these differences even clearer.

\subsection{Quantitative analysis}

The main focus of the analysis was to compare the way the five semantic categories Path, Direction, Region, Manner and Landmark were expressed in the Telugu and Thai data, in terms of both types and tokens. We begin by providing some general descriptive statistics where we do not "normalize" the data, given that the total number of self-motion event descriptions in the data was more or less similar. Then we offer inferential statistics where we do control for all relevant factors, using regression analysis. The results are summarized in Table 3, and all types with their respective number of tokens are given in Appendix A.

Table 3: Types and tokens for each of the semantic categories coded in the data.

\begin{tabular}{llllll}
\hline Category & Form class & Telugu (types) & $\begin{array}{l}\text { Telugu } \\
\text { (tokens) }\end{array}$ & $\begin{array}{l}\text { Thai } \\
\text { (types) }\end{array}$ & $\begin{array}{l}\text { Thai } \\
\text { (tokens) }\end{array}$ \\
\hline Path & Verb & 4 & 10 & 8 & 151 \\
Total & Case/Prep & 2 & 174 & 3 & 44 \\
Direction & Verb (VC) & 2 & 184 & 11 & 197 \\
& Verb (GC) & 2 & 108 & 2 & 274 \\
Total & Noun (OC) & 2 & 30 & 2 & 104 \\
Manner & & 5 & 143 & 4 & 378 \\
& Verb & 10 & 91 & 24 & 179 \\
Total & Adverb & 13 & 37 & 15 & 38 \\
Region & Ideophone & 2 & 3 & 8 & 12 \\
Landmark & & 25 & 131 & 47 & 229 \\
\hline
\end{tabular}

Starting with the category Path, the first surprising result (for what Talmian typology would regard as a "verb-framing language") was that the Telugu participants used only four verb types for a total of ten times. The two case markers, on the other hand, were used extensively. In Thai, the situation was rather the opposite as the narrators preferred to express Path in verbs - more often than in Telugu in terms of both types and tokens — and used relatively few prepositions. Disregarding these differences, the overall rates of Path-expressions were quite similar in the two languages (Telugu: 184; Thai: 197). With respect to Direction, there were few differences in terms of types and proportions between the two languages, with VC (deictic) direction expressions dominating, followed by GC (vertical) expressions, and only two types and five instances of OC-Direction in Telugu. However, in terms of tokens, we can see that the Thai speakers expressed the category of Direction much more often than the Telugu speakers. Turning to Manner, the same three form classes were used by the Telugu and Thai narrators, with verbs being most frequent, followed by adverbs and a limited number of ideophones. However, while the numbers for types and tokens of adverbs were very similar, the Thai speakers used twice as many verbs. Concerning ideophones, these were also better represented in the Thai data, which was surprising, given that such expressions are characteristic of everyday spoken and written Telugu (Duggirala 2016). 
As for the more static categories Region and Landmark, we see a very different relation between the two languages. As shown in the previous section, Telugu uses nominals while Thai uses mostly prepositions to express the category Region. While the number of types used by the speakers of both languages was nearly the same, the Telugu participants used nearly twice as many tokens. Finally, the category Landmark was expressed more often in Telugu (229 tokens) than in the Thai data (196 tokens), despite the fact that there were slightly fewer types. Another notable point is that the speakers of Telugu used more Landmark-referring anaphorical expressions (40 tokens) than the Thai speakers (6 tokens), see Appendix A, (e).

Figure 1 displays the proportions of all clauses expressing translocation in the data (406 for Thai and 291 for Telugu, see Table 1). We conducted mixed-effects logistic regression analyses to establish whether there were any statistically significant differences between the two participant groups for the five semantic categories. It should be noted that this type of analysis accounts for the correlated responses within speakers, as speakers were included as a random predictor and language was included as the fixed predictor. In other words, this excludes the possibility that the differences between the languages are due to individual speakers. The results of the regression analysis are shown in Appendix B.

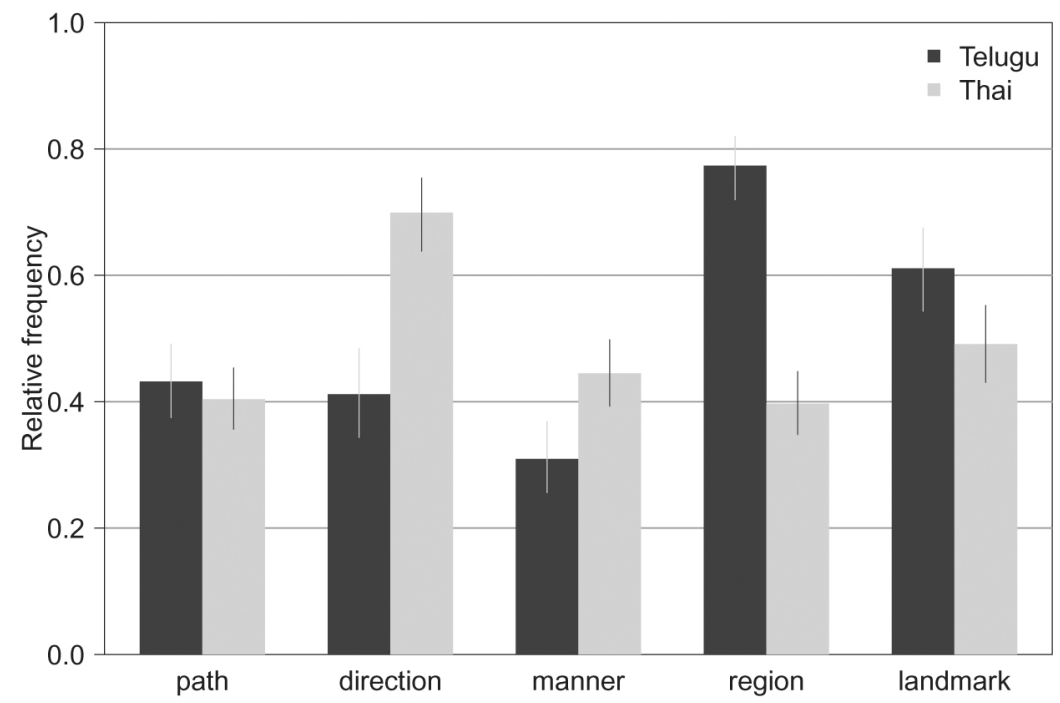

Figure 1: Proportions of Path, Direction, Manner, Region, and Landmark expressions in the Telugu and Thai frog story data.

For Path, the proportion of expressions was $43 \%$ for Telugu and $41 \%$ for Thai, a difference that was not statistically significant $(p=0.500)$. Direction was expressed in $41 \%$ of the clauses for Telugu, while for the Thai group the proportion was as high as $70 \%$, which was a difference that was highly significant $(p=0.000)$. For Manner, approximately $31 \%$ of all clauses expressed the category in Telugu, compared with $44 \%$ of clauses in Thai, which was also a statistically significant difference $(p=0.000)$. For the category Region, the proportion of expressions was $77 \%$ for Telugu, but only $40 \%$ for Thai, a difference that was likewise statistically significant $(p=0.000)$. For Landmark, the proportion of expressions was $60 \%$ for the Telugu and $49 \%$ for the Thai group, which was also significantly different $(p=0.014)$.

Following the comparison between the languages in terms of semantic categories, we grouped the form classes into (ad)verbal (verbs and adverbs) and (ad)nominal (nouns, case markers, and prepositions) and performed the same analyses - leaving out ideophones as they belong to neither group, as discussed on Section 3.3. Figure 2 shows that motion event descriptions from the two languages differ significantly both in terms of form and content: the Thai speakers had a higher proportion of verbal and adverbal expressions per clause $(p$ $=0.000)$, while the Telugu speakers had more nominal and adnominal expressions $(p=0.000)$. The results of the regression analysis are shown in Appendix B. 


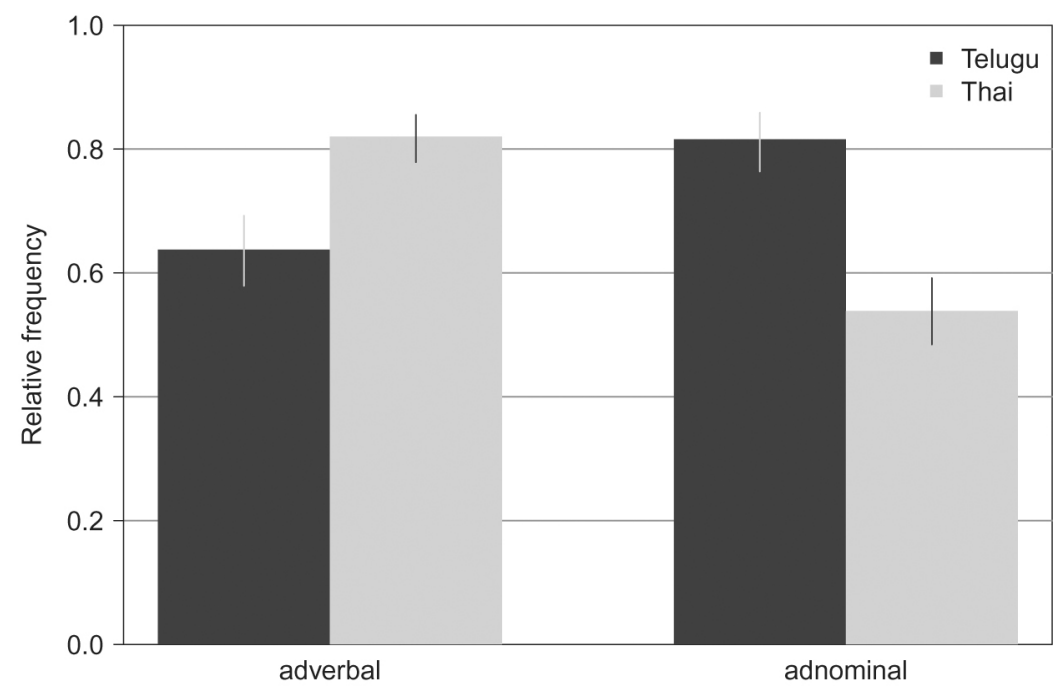

Figure 2: Comparing total number of (ad)verbal and (ad)nominal expressions in Telugu and Thai.

To summarize, the descriptive and inferential statistical analyses of our data allow us to make the following generalizations:

- The speakers of both languages expressed the category Path almost equally often, but in different ways: while the Telugu speakers used case-marking almost exclusively, the Thai speakers preferred to express Path through verbs.

- The Thai participants expressed Direction significantly more often than the Telugu narrators, as reflected in a higher number of Viewpoint-based (deictic) and Geocentric expressions. The most likely explanation for this difference between the languages is the capacity of Thai serial verb constructions to incorporate easily Direction through deictic and ascend/descend-type verbs, possibly in combination, as well as to distribute Direction over verbs and compound nominals, while these options are absent (or at least uncommon) in Telugu (see Table 2).

- The category Manner was also expressed significantly more often by the Thai than the Telugu speakers, which was due above all to the greater number of verbs, and to some degree ideophones, but not adverbs. Again, the structural feature of serial verbs, with Manner-verbs in first position, and the tendency to distribute it over several form classes, are the most likely explanation for this difference.

- Conversely, the Telugu speakers expressed both Region and Landmark significantly more often than the Thai speakers. This difference follows naturally from the nominal status of these expressions, as the case-markers, which serve as the default way to express Path in Telugu, require such nominals structurally.

On the whole, the results show that motion event expressions in Thai and Telugu, at least in the present data, differ significantly both in terms of content and form, and that these differences may be attributed to different structural features of the languages: serial verbs and case-marking, respectively.

\section{Summary and conclusions}

Many have argued that we need to move beyond the constraints of the original Talmian binary typology of motion event expression (e.g. Beavers et al. 2010; Levinson and Wilkins 2006 and 2004; Croft et al. 2010; Fagard et al. 2013) due to a number of by now well-documented problems with the model. In Section 2, we focused on four such issues: additional language types, extensive variation, other relevant expressions than "verbs and satellites," and alternative analyses of the relevant semantic categories. But rather than taking these simply as weaknesses of the original model, we construed them as challenges for the theory of Holistic Spatial Semantics, which, despite being first proposed some 20 years ago, has been only recently applied to motion event analysis (Fagard et al. 2013; Blomberg 2014) and with promising results.

As a first step, we argued that HSS provides conceptual and analytical tools for resolving the four controversies in motion event typology. The set of seven necessary and three additional semantic categories is at least potentially universal, as they are both grounded in human embodiment and flexible enough to adapt to the conventions of particular languages (Zlatev 1997). The mapping patterns between (conventionalized) semantic 
categories and language-specific form classes are the HSS equivalent to constructions (Croft et al. 2010), and the options of conflation, distribution, composition, and covert expression provide an open-ended expressive potential in the domain of motion semantics, awaiting systematic comparisons across languages without prior assumptions on the number of language types. This implies the need for widening the empirical data set, using analyses based both on native-speaker intuitions and language use.

Thus, as a second step in the argumentation and to test the applicability of the HSS framework, we performed a qualitative and quantitative comparison of motion event descriptions in Thai and Telugu based on the Frog-story narrative elicitation procedure. Despite some preliminary similarities, a careful analysis of specific, comparable data showed that the two languages are indeed quite different. The Telugu participants in our study used a minimum number of Path verbs in contrast to extensive ablative and dative case marking, in combination with nominals expressing Region and/or Landmark. The Thai speakers, on the other hand, relied on serial verb constructions and, to some extent, prepositions for the expression of Path. The Thai speakers encoded Direction and Manner significantly more often than the Telugu speakers, who relied more on nominals to express the categories Region and Landmark. These differences can be straightforwardly explained given the different structural characteristics and common expression patterns in the two languages.

Overall, these qualitative and quantitative differences clearly show that the two languages should not be considered as belonging to the same type. Indeed, the main reason that one may be tempted to treat Thai and Telugu as typologically similar is due to the fact that neither fit any of the two classical types of Talmian motion event typology, which is a purely negative criterion. Once we abandon this binary "straight-jacket," we become free to cluster motion event descriptions, along with the structural patterns of specific languages, in as many types as we need, based on clearly defined criteria such as those proposed by the HSS framework.

Still, are we capable of being more specific about the expected number of language types in motion semantics? First, we need to state clearly that we do not see a conflict between a typology of language types and a typology of language constructions, as "constructions are not 'atoms' that a language can pick or leave at random" (Fagard et al. 2013: 337), but rather constitute, to repeat, structured inventories of constructions with constraints on co-occurrence. Having said this, we should emphasize that it is indeed outdated to treat languages as monolithic, reified systems - rather, they should be treated as conglomerates of more or less variable social norms and usage patterns (Berthele 2013; Zlatev and Blomberg, in press). The point is not to fall in one of the two extremes of either reifying languages or, conversely, to dispense with them altogether and only to look at individual utterances.

From such a perspective, how many different language types — understood as clusters with distinct prototypes - can we expect to find in a motion event typology based on our theory? We started by citing and agreeing with Beavers et al. (2010) that "any viable account should illuminate why Talmy's typology is so close to being right." Given our theoretical framework and empirical findings, we can indeed "illuminate" this, as we can make the prediction that further studies will support the original proposal that languages like Spanish and French, on the one hand, and languages like Swedish and English, on the other, correspond to clusters with distinct prototypes. However, these will appear as only two such clusters, while serial verb languages like Thai (e.g. Ewe and Vietnamese) and languages like Telugu (e.g. Tamil and Finnish) will fall into clusters that are distinct from these, as well as from each other, thus giving us (at least) four distinct typological prototypes. From this perspective, we can see languages like Italian (sharing features of the clusters instantiated by Spanish on the one hand and Swedish on the other) or Basque (sharing features with the clusters exemplified by Telugu on the one hand and Spanish on the other) should indeed be viewed as mixed types (e.g. Ibarretxe-Antunano and Hijazo-Gascón 2012), making them hard to fit in any binary, or ternary, motion event typology.

\section{Acknowledgements}

We wish to thank two anonymous reviewers and Iraide Ibarretxe-Antunano for many helpful comments on a previous version of this paper, and to Soraya Osathanonda for assistance in coding the Thai data. The work was in part supported by the project Phenomenology and Typology of Motion (PATOM), funded by the Swedish Research Council, grant 2015-01583.

\section{List of abbreviations}

3SG third person singular

ABL ablative

ACC accusative 
Adj adjective

Adv adverb

AGR agreement

AUX auxiliary

CAUS causative

DAT dative

DEF definitive

DEM demonstrative

GC Geocentric

INT interjection

LM landmark

LOC locative

$\mathrm{N}$ noun

NOM nominative

NP noun phrase

OC Object-Centered

Prep preposition

PRF perfect

PROG progressive

Pron pronoun

Prt particle

PST past

PTCP participle

SG singular

$\mathrm{V}$ verb

VC Viewpoint-Centered

\section{A Appendix}

(a) Path types and tokens in the data: Telugu (left) and Thai (right)

\begin{tabular}{|c|c|c|}
\hline Verb & $\begin{array}{l}\text { ceerukonu ('arrive'): } 4 \\
\text { tappipoovu ('escape'): } 3 \\
\text { bayata padu ('exit'): } 2 \\
\text { daatu ('cross'): } 1\end{array}$ & $\begin{array}{l}\text { Pjok ('exit'): } 63 \\
\text { taam ('follow'): } 35 \\
\text { khâw ('enter'): } 19 \\
\text { klàp ('return'): } 14 \\
\text { nǔi ('escape'): } 13 \\
\text { thuǔn ('reach'): } 4 \\
\text { khâam ('cross'): } 2 \\
\text { phàan ('pass'): } 1\end{array}$ \\
\hline Case/Prep & $\begin{array}{l}-k i /-k u\left({ }^{\prime} \text { to' }^{\prime}\right): 106 \\
\text { numci ('from'): } 68\end{array}$ & $\begin{array}{l}\text { càak ('from'): } 41 \\
\text { thuǔn ('up to'): } 3 \\
\text { thaan ('towards'): } 1\end{array}$ \\
\hline
\end{tabular}

(b) Direction types and tokens in the data: Telugu (left) and Thai (right)

\begin{tabular}{lll}
\hline Verb (VC) & vellu / poovu ('go'): 59 & pay ('go'): 156 \\
& vaccu ('come'): 49 & maa ('come'): 118 \\
Verb (GC) & ekku ('ascend'): 29 & lon ('descend'): 57 \\
& digu ('descend'): 1 & khuîn ('ascend'): 47 \\
Noun (OC) & mumduku ('forward'): 3 &
\end{tabular}


(c)Manner types and tokens in the data: Telugu (left) and Thai (right)

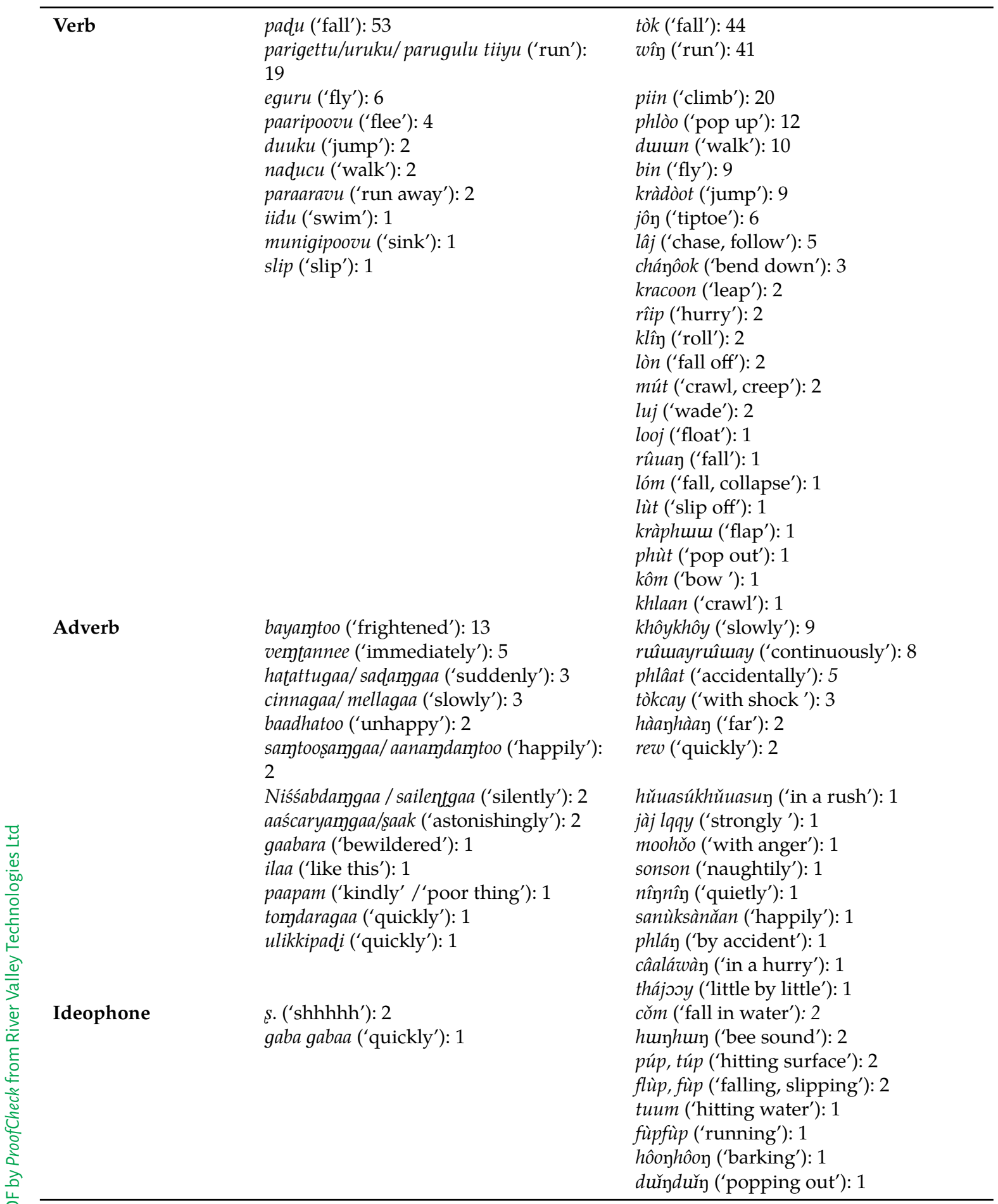

(d) Region types and tokens in the data: Telugu (left) and Thai (right)

\begin{tabular}{lll}
\hline Noun/Prep & loo/loopala ('in(side)'): 132 & nay ('in'): 78 \\
& kimda ('below'): 45 & bon ('on, above'): 47 \\
& bayata ('out'): 45 & thîi ('at'): 22 \\
& paina ('above'): 30 & tâay ('under'): 6 \\
miida ('above/on'): 25 & nôok ('out'): 4 \\
daggara ('near'): 18 & khâan ('side'): 4 \\
pakkana ('side'): 11 & lăy ('behind'): 4 \\
mumdu ('front'): 4 & ráwàay ('around'): 1
\end{tabular}


cuttu ('around'): 2

venaka ('back'): 2

civara ('end'): 1

vaipu ('side'): 1

madhyana ('between'): 1 nuîua ('above'): 1

rôop ('around'): 1

lâan ('below'): 1

bûuan sǔun ('above-side'): 1

(e) Landmark types and tokens in the data: Telugu (left) and Thai (right)

\begin{tabular}{|c|c|c|}
\hline Noun & 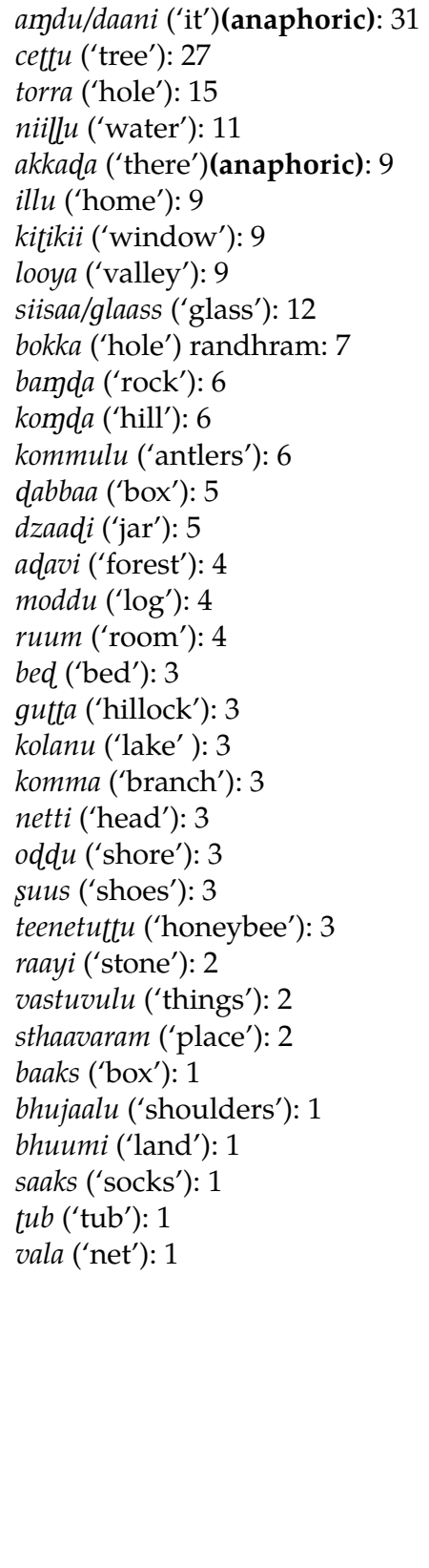 & 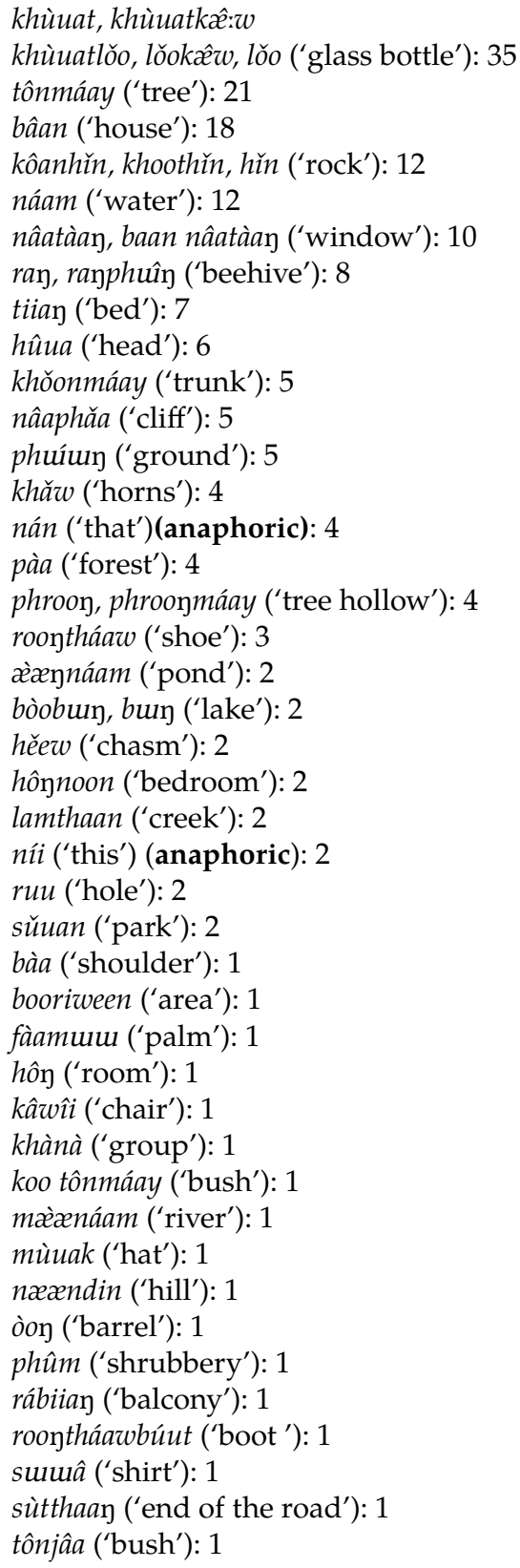 \\
\hline
\end{tabular}

\section{B Appendix}

(1) Results for the five categories from the binomial regression analysis, with Telugu represented by the Intercept, and compared to Thai; significant differences are observed for Direction and Manner (with higher values for Thai) and for Region and Landmark (with higher values for Telugu).

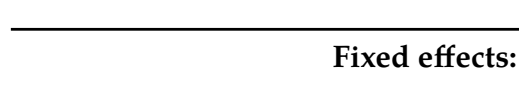

Path

(Intercept) 


\begin{tabular}{llllll} 
& Thai & -0.116 & 0.156 & -0.744 & 0.460 \\
Direction & (Intercept) & -0.356 & 0.146 & -2.432 & 0.015 \\
& Thai & 1.200 & 0.201 & 5.971 & 0.000 \\
Manner & (Intercept) & -0.802 & 0.132 & -6.076 & 0.000 \\
& Thai & 0.581 & 0.171 & 3.405 & 0.001 \\
Region & (Intercept) & 1.229 & 0.143 & 8.593 & 0.000 \\
\multirow{3}{*}{ Landmark } & Thai & -1.648 & 0.177 & -9.317 & 0.000 \\
& (Intercept) & 0.418 & 0.140 & 3.243 & 0.001 \\
\hline
\end{tabular}

(2) Results from the regression analysis, showing significantly more (ad)verbal expressions per clause in the Thai data, and significantly more (ad)nominal in the Telugu data.

\begin{tabular}{llllll}
\hline & Fixed effects: & & & & \\
(ad)verbal & & Estimate & $S E$ & $z$ & 0.000 \\
& (Intercept) & 0.565 & 0.123 & 5.602 & 0.000 \\
(ad)nominal & Thai & 0.953 & 0.178 & 9.343 & 0.000 \\
& (Intercept) & 1.489 & 0.157 & -7.013 & 0.000 \\
\hline
\end{tabular}

\section{Notes}

1 In Telugu, the case marker $k i$ has undergone considerable semantic extension and serves multiple case functions that include non-spatial meanings (Subbarao and Bhaskararao 2004). For the present analysis, we gloss it as Dative, even when its specific meaning is that of Allative (indicating the End value of category Path, see Section 3).

2 At least this is so when expressing a "simplex" motion event. It is possible for what Takahashi (2009) calls "arrival verbs" like thuǔn ('reach') and yùt ('stop') to follow such a sequence, giving rise to a complex motion event, where "the two components express different, albeit serial, events (i.e. locomotion and arrival)" (ibid: 181)

3 E.g. "Anything that is not a verb root but encodes an event component will be analyzed as a satellite." (Croft et al. 2010: 206)

4 We should emphasize that the relevant sense of boundedness is here spatial rather than temporal, corresponding to the notion of q(uality)-boundedness rather than to t(emporal) boundedness in Croft (2012) two-dimensional model of aspect. Thus, for example: He went to school and He was going to school, are equally q-bounded, expressing Path:End, through the combination of the preposition and Landmark-nominal, even though they differ in t-boundedness, an aspectual distinction that we treat as orthogonal (Zlatev et al. 2010) and do not address in this paper.

5 It can be noted that there is no special semantic category devoted to the expression of translocation vs. location, as this distinction falls out from the combination of the categories of Path/Direction, and Motion, with translocation always invoving both, while location only the latter, with either negative or positive value.

6 In effect, this is a generalization of the notion of "double framing" (Croft et al. 2010) since it is not only Path that can be expressed in two (or more) morphemes, but any of the other categories as well. Note also that distinguishing the categories Path and Region allows us to make a clear distinction between prepositions in French that express Path (de 'from' and $a$ 'to'), often together with the verb (Blomberg 2014), and those that express overtly only Region (dans, 'in') (see Aurnague 2015).

7 The Telugu data used was collected as part of a project on Spatial Semantic Knowledge and Use among Multilinguals (2009-2012) funded by Department of Science and Technology (Government of India). The Thai data was originally collected by the First Language Acquisition of Thai (2000-2001) project, funded by the Swedish Foundation for Internationalization of Research (STINT), in cooperation with Chualongkorn University.

8 See Zlatev and Yangklang (2004) for details on how the Thai transcriptions were obtained and segmented into utterances, clauses, and words. The Telugu descriptions were analyzed similarly, using the criterion that each clause should have only one finite verb. The coding of the Telugu data was performed by the first author, a native speaker of Telugu, and of the Thai data by the second author, together with a Thai project assistant, Soraya Osathanonda.

9 We have no explanation of why the Thai participants provided more detailed descriptions than the Telugu participants apart from observing that the first used a physical copy of the stimulus book while the latter used a digital copy, which may possibly have led them to construe the narrative in a more picture-by-picture manner.

10 This seems to be the case for every "adverbial noun" apart from loo ('in'), which may indicate that the latter has gone further in grammaticalization, becoming a regular postposition.

11 Apart from Direction, these two verbs also involve Manner, as there is an implication of volitional movement. For instance, the verb ekku ('ascend') is needed to express the event of intentionally going up the stairs or up the tree, where using the deictic verb vellu ('go') would not be adequate. Similarly, digu ('descend') would not be appropriate in the case of falling, clearly a non-volitional case of "descending." 12 An expression such as thǔy expressing Path:End (see Section 4.2.1) could follow this sequence, but while we agree with Takahashi (2009) that it could in principle function as an "arrival verb" thǔn ('reach'), in all cases in our data it was followed by a nominal, making it more straightforward to treat it as a "terminative" preposition.

13 The verb combinations in examples (31d) and (31e) would be grammatical if there were a clause break after the deictic verb maa, interpreting what follows as a purpose clause with an elliptic subjunction "s/he came, so as to climb (up)." 


\section{References}

Ameka, F. K. \& ]. Essegbey. 2006. Elements of the grammar of space in Ewe. In S. C. Levinson \& D. P. Wilkins (eds.), Grammars of space: Explorations in cognitive diversity, 359-399. Cambridge: Cambridge University Press.

Ameka, F. K. \& ]. Essegbey. 2013. Serialising languages: Satellite-framed, verb-framed or neither. Chana Journal of Linguistics 2(1). 19-38.

Aske, J. 1989. Path predicates in English and Spanish: A closer look. Annual Meeting of the Berkeley Linguistics Society 15. 1-14.

Aurnague, M. 2015. Motion verbs and special PPs in French: From Spatio-temporal structure to asymmetry and goal bias. Doctoral dissertation, CLLEERSS.

Barðdal, J. 2013. Construction-based historical-comparative reconstruction. In T. Hoffmann \& G. Trousdale (eds.), The Oxford handbook of construction grammar, 438-457. Cambridge: Cambridge University Press.

Beavers, J., B. Levin \& S. W. Tham. 2010. The typology of motion events revisited. Journal of Linguistics 46. 331-377.

Berman, R. A. \& D. I. Slobin (eds). 1994. Relating events in narrative: A cross-linguistic developmental study. Hillsdale: Lawrence Erlbaum.

Berthele, R. 2013. Disentangling manner and path: Evidence from varieties of German and Romance. In J. Goschler \& A. Stefanowitsch (eds.), Variation and change in the encoding of motion events, 41-55. Amsterdam: John Benjamin.

Blomberg, J. 2014. Motion in Language and Experience: Actual and Non-Actual Motion in Swedish, French and Thai. Doctoral dissertation. Lund: Lund University.

Bohnemeyer, ]., N. J. Enfield, J. Essegbey, I. Ibarretxe-Antunano, S. Kita, F. Lupke \& F. Ameka. 2007. Principles of event segmentation in language: The case of motion events. Language 83(3). 495-532.

Chen, Liang \& ]. Guo. 2009. Motion events in Chinese novels: Evidence for an equipollently-framed language. Journal of Pragmatics 41(9). 1749-1766.

Croft, W. 2003. Typology and universals. Cambridge: Cambridge University Press.

Croft, W. 2012. Verbs: Aspect and causal structure. Oxford: Oxford University Press.

Croft, W., J. Barðdal, W. Hollmann, V. Sotirova \& C. Taoka. 2010. Revising Talmy's typological classification of complex event constructions. In H. Boas (ed.), Contrastive construction grammar, 201-235. Amsterdam: John Benjamins.

DeLancey, S. 1981. An interpretation of split ergativity and related patterns. Language 57(3). 626-657.

Dingemanse, M. 2012. Advances in the cross-linguistic study of ideophones. Language and Linguistics Compass 6(10). 654-672.

Duggirala, V. 2011. Verbs of motion and language use: Reflections on research frameworks. In R. K. Mishra \& N. Srinivasan (eds.), Languagecognition interface: State of the art, 158-179. Muenchen: Lincom Europa.

Duggirala, V. 2016. On the iconicity of ideophones in Telugu. Poster presented at the International Symposium on Mimetics in Japanese and Other Languages of the World. Tachikawa, Tokyo.

Ekström, J. 2015. The expression of non-actual motion in Swedish Sign Language. BA Thesis. Lund: Lund University.

Fagard, B., J. Zlatev, A. Kopecka, M. Cerruti \& ]. Blomberg. 2013. The expression of motion events: A quantitative study of six typologically varied languages. Annual Meeting of the Berkeley Linguistics Society 39(1). 364-379.

Garrett, A. 1990. The origin of NP split ergativity. Language 66(2). 261-296.

Heine, B. \& T. Kuteva. 2007. The genesis of grammar: A reconstruction. Oxford: Oxford University Press.

Ibarretxe-Antuñano, I. 2004. Language typologies in our language use: The case of Basque motion events in adult oral narratives. Cognitive Linguistics 15(3). 317-349.

Ibarretxe-Antuñano, I. 2009. Path salience in motion events. In ]. Guo, E. Lieven, N. Budwig, S. Ervin-Tripp, K. Nakamura \& S. Őzçaliş̧an (eds.), Crosslinguistic approaches to the psychology of language: Research in the tradition of Dan Isaac Slobin, 403-414. New York: Psychology Press.

Ibarretxe-Antuñano, I. 2017. Basque ideophones from a typological perspective. Canadian Journal of Linguistics 62(2). 196-220.

Ibarretxe-Antuñano, I. \& A. Hijazo-Gascón. 2012. Variation in motion events: Theory and applications. In L. Filipovic \& K. Jaszczolt (eds.), Space and time in languages and cultures: Linguistic diversity, 349-371. Amsterdam: Benjamins.

Imbert, C. 2012. Path: Ways typology has walked through it. Language and Linguistics Compass 6(4). 236-258.

Indrambarya, K. 1995. Are there prepositions in Thai? In M Alves (ed.), Papers from the third annual meeting of the southeast Asian linguistic society, 101-118. Arizona: Arizona State University.

Intrarat, C. 1996. Crammaticalization of Verbs into Prepositions in Thai. PhD dissertation. Bangkok: Chulalongokorn University.

Jackendoff, R. 1992. Semantic structures. Cambridge: MIT Press.

Krishnamurti, B. \& J. P. L. Cwynn. 1985. A grammar of modern Telugu. Delhi: Oxford University Press.

Langacker, R. W. 1987. Foundations of cognitive grammar: Theoretical prerequisites, vol. 1. Stanford: Stanford University Press.

Levinson, S. C. 2003. Space in language and cognition: Explorations in cognitive diversity, vol. 5. Cambridge: Cambridge University Press.

Levinson, S. C. \& D. P. Wilkins. 2006. Crammars of space: Explorations in cognitive diversity. Cambridge: Cambridge University Press.

Matsumoto, Y., et al. 2003. Typologies of lexicalization patterns and event integration: Clarifications and reformulations. In S. Chiba (ed.),

Empirical and theoretical investigations into language: A festschrift for Masaru Kajita, 403-418. Tokyo: Kaitakusha.

Mayer, M. 1969. Frog, where are you?. New York: Dial Press.

Naidu, V. \& V. Duggirala. 2011. On verbalizing motion in Telugu. Indian Linguistics 72. 180-194.

Özcaliskan, S. 2013. Ways of crossing a spatial boundary in typologically distinct languages. Applied Psycholinguistics 36(2). $485-508$.

Panupong, V. 1989. The structure of Thai: Crammatical system. Bangkok: Ramkhamhaeng University.

Prasithrathsint, A. 2010. Crammaticalization of nouns into prepositions in Thai. Journal of Language and Linguistics 28(2). 68-83.

Regier, T. 1996. The human semantic potential: Spatial language and constrained connectionism. Cambridge: The MIT Press.

Sinha, C. \& T. Kuteva. 1995. Distributed spatial semantics. Nordic Journal of Linguistics 18(2). 167-199.

Slobin, D. I. 2004. The many ways to search for a frog: Linguistic typology and the expression of motion events. In S. Stromqvist \& L. Verhoeven (eds.), Relating events in narrative: Typological and contextual perspectives, 219-258. Mahwah: Erlbaum. 
Slobin, D. I. 2006. What makes Manner of Motion salient? Explorations in linguistic typology, discourse, and cognition. In M. Hickmann \& S. Robert (eds.), Space in languages: Linguistic systems and cognitive categories, 59-81. Amsterdam: John Benjamins.

Slobin, D. I. 2017. Typologies and languages use. In I. Ibarretxe-Antuñano (ed.), Motion and space across languages and applications, 419-446. Amsterdam: Benjamins.

Slobin, D. I. \& N. Hoiting. 1994. Reference to movement in spoken and signed languages: Typological considerations. Annual Meeting of the Berkeley Linguistics Society 20(1). 487-505.

Slobin, D. I., I. Ibarretxe-Antunano, A. Kopecka \& A. Majid. 2014. Manners of human gait: A crosslinguistic event naming study. Cognitive Linguistics 25(4). 701-741.

Strömqvist, S. \& L. T. Verhoeven (eds). 2004. Relating events in narrative: Typological and contextual perspectives, vol. 2. Mahwah: Erlbaum.

Subbarao, K. V. \& P. Bhaskararao. 2004. Non-nominative subjects in Telugu. In K. V. Subbarao \& P. Bhaskararao (eds.), Typological studies in language: Non-nominative subjects, 161-196. Amsterdam: John Benjamins.

Subrahmanyam, P. S. 1971. Dravidian verb morphology: A comparative study. Annamalainagar: Annamalai University.

Takahashi, K. 2009. Arrival expression in Thai. Journal of the Southeast Asian Linguistics Society 2. 175-193.

Talmy, L. 1985. Lexicalization patterns: Semantic structure in lexical forms. In T. Shopen (ed.), Language typology and syntactic description, volume 3: Crammatical categories and the Lexicon. Cambridge: Cambridge University Press.

Talmy, L. 1991. Path to realization: A typology of event conflation. Annual Meeting of the Berkeley Linguistics Society 17(1). 480-519.

Talmy, L. 2000a. Toward a cognitive semantics: Concept structuring systems, vol. 1. Cambridge: MIT press.

Talmy, L. 200ob. Toward a cognitive semantics: Typology and process in concept structuring, vol. 2. Cambridge: MIT Press.

Talmy, L. 2009. Main verb properties and equipollent framing. In J. Guo, E. Lieven, N. Budwig, S. Erwin-Tripp, K. Nakamura \& S. ŐZçaliskan (eds.), Cross-linguistic approaches to the psychology of language: Research in the tradition of Dan Isaac Slobin, 389-402. New York: Psychology Press.

Thepkanjana, K. 1986. Serial Verb Construction in Thai. Doctoral dissertation. Ann Arbor: University of Michigan.

Wagemans, J., J. H. Elder, M. Kubovy, S. E. Palmer, M. A. Peterson, M. Singh \& R. von der Heydt. 2012. A century of Cestalt psychology in visual perception: I. Perceptual grouping and figure-Ground organization. Psychological Bulletin 138(6). 1172-1217.

Wälchli, B. 2001. A typology of displacement (with special focus on Latvian). Sprachtypologie und Universalienforschung 54(3). $298-323$.

Zlatev, J. 1997. Situated embodiment: Studies in the emergence of spatial meaning. Stockholm: Cotab.

Zlatev, J. 2003. Holistic spatial semantics of Thai. In E. Casad \& G. Palmer (eds.), Cognitive linguistics and Non-Indo-European languages, $305-336$. Berlin: Mouton De Gruyter.

Zlatev, J. 2007. Spatial semantics. In D. Geeraerts \& H. Cuyckens (eds.), The Oxford handbook of cognitive linguistics, 318-350. Oxford: Oxford University Press.

Zlatev, J. \& J. Blomberg. 2016. Embodied intersubjectivity, non-actual motion expressions and the sedimentation of meaning. Nordic journal of Linguistics 39(2). 1-24.

Zlatev, J. and Blomberg, J. in press. Norms of language: What kinds and where from? Insights from phenomenology. In A. Mäkilähde and V. Leppänen (eds.), Norms and normativity in language and in linguistics. Amsterdam: Benjamins.

Zlatev, J., J. Blomberg \& C. David. 2010. Translocation, language and the categorization of motion. In V. Evans \& P. Chilton (eds.), Language, cognition, and space: The state of the art and new directions, 389-418. London: Equinox.

Zlatev, J. \& C. David. 2003. Motion event constructions in Swedish, French and Thai: Three different language types. Manusya: Journal of Humanities 6. 18-42.

Zlatev, J., V. Naidu, J. Blomberg \& V. Duggirala. 2015. Motion in Thai and Telugu: Two “deviant” languages? Presented at SALC5. Trondheim: University of Trondheim.

Zlatev, J. \& P. Yangklang. 2004. A third way to travel. In S. Strömqvist \& L. Verhoeven (eds.), Relating events in narrative: Typological and contextual perspectives, 191-218. Mahway: Lawrence Ernbaum.

Zvelebil, K. V. 1977. A sketch of comparative dravidian morphology (part I). Mouton: The Hague.

\section{Bionotes}

Viswanatha Naidu is an assistant professor at the University of Hyderabad and working towards his PhD in Linguistics at the University of Gothenburg. His primary research interests are within the area of cognitive linguistics, specifically motion event typology, cutting and breaking events, and body part categorization, with focus on Dravidian languages.

Jordan Zlatev is a professor of General Linguistics at Lund University, working at the Division for Cognitive Semiotics of the Centre for Languages and Literature. His research focuses on consciousness and language in relation to other semiotic systems like gestures and depiction. He is the author of Situated Embodiment (1997), co-editor of The Shared Mind (2008) and Moving Ourselves, Moving Others (2012), and has published over 80 articles in peer-reviewed journals and books. He is editor-in-chief of Public Journal of Semiotics. 
Vasanta Duggirala obtained her doctoral degree in Audiology from the University of Memphis, Tennessee in 1986. During 1987-2015, she was on the teaching faculty of the Department of Linguistics at Osmania University in Hyderabad. In recent years, she has worked on the research project Language and Experience: A typology of Telugu Ideophones as part of the Emeritus Fellow scheme of the University Grants Commission in New Delhi. Her research interests and publications deal with different aspects of applied linguistics, literacy studies, gender studies, and translation.

Joost van de Weijer obtained his Ph.D. from the Max Planck Institute for Psycholinguistics in 1998. He is currently employed at the Division for Linguistics and Phonetics and at the Humanities Lab, both at Lund University. His main research interests are experimental linguistics and quantitative data analysis.

Simon Devylder is a researcher at the Division for Cognitive Semiotics in Lund University's Centre for Languages and Literature. His main research interests are polysemiotic communication, semantic typology of body representation and motion, and mereology. His research more broadly concerns the interaction of semiotic systems, sensory modalities, cognition, and culture in meaning making.

Johan Blomberg obtained his PhD in General Linguistics from Lund University in 2014 and works as researcher at the Division for Cognitive Semiotics of Lund University. His research is primarily concerned with the relation between language and cognition, focusing on space and motion. 